(8)

Informal Report

by

William R. Ellis
UC.20

Reporting Date: July 1975

Issued: July 1975

$+8$

An Affirmative Action ; Equal Opporlunity Employer 
In the interest of prompt distribution, this report was not edited by the Technical Information staff.

\author{
Pristed in the United Staten of America. Available trom \\ Notional Technical Information Service \\ US Departmeni it Cnmmerce \\ 5285 Port Royal Pood \\ Spriagtield, VA 22151 \\ Price. Printed Copy \$4.00 Nicrotiche \$2.25
}

This report wat prepared at an eccoumi of work spoasored

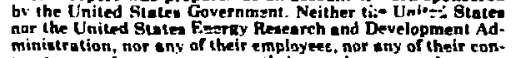
tractors, ubcantractors. of their employes. makee eny werranty, express or implied, or nusumes nay letal liabllity or

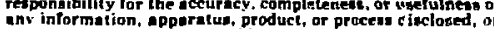
repretents that its une would not infringe privately owned

rixhts. 
Abstract ........................ 1

I. INTRODUCTION ......................... . . 1

II. BRIEF DESCRIPTION OF THE LTPF . . . . . . . . . . . . . . 2

A. Geometry . . . . . . . . . . . . . . . . . . . 2

B. Plasma Physics Assumptions... . . . . . . . . . . . 3

C. Neutron Current Requirements............... . 4

III. SCALING RELATIONS FOR THE LTPF . . . . . . . . . . . . . . . 4

A. Parameterizing the Neutron Current . . . . . . . . . . . . 4

1. Plasma Pressure Balance. . . . . . . . . . . . 5

2. Shock-Heating Requirements ............. . 5

3. End-loss Time................... 6

4. D-T Fusion Cross-Section.............. . 6

5. Power Supply Considerations .. . . . . . . . . . 7

B. Deriving the Scaling Relations............. 8

IV. MAXIMIZING THE NEUTRON CURRENT ................... 12

A. Optimum Ion Temperature . . . . . . . . . . . . . . . 12

B. Optimum Coil and Tube Dimensions............. 12

C. Optim $E_{\theta}$. . . . . . . . . . . . . . . . . . . . . . 13

D. Optimum Quality Factor and Joule Power Loss... . . . . . 13

E. Optimum End-Loss Parameter ............. . . 14

V. TWO LTPE POINT DESIGNS . . . . . . . . . . . . . . . . 15

A. Point Design A (Regular Sinusoidal Waveform) . . . . . . . 15

B. Point Design B (Intermittent Trapezoidal Waveform) . . . . 18

VI. POWER SUPPLIES . . . . . . . . . . . . . . . . . . 20

VII. SUMMARY AND CONCLUUSIONS . . . . . . . . . . . . . . . . 21

Acknowled-gments . . . . . . . . . . . . . . . 22

Appendix I - Neutronics Terminology . . . . . . . . . . . 23

Appendix II - Plasma Heating in the LTPF . . . . . . . . . 25

A. Derivation of Staged-Heating Equations........... . 25

B. Radial Dependence of $\mathrm{E}_{\theta} \cdot$. . . . . . . . . . . . . 28 
Appendix III - Electrical Circuit Parameters . . . . . . . . . 30

A. Parameters for Point Designs A and B. . . . . . . . . . . 30

B. Capacitor Bank Characteristics (Point Design A) . . . . . . . 32

C. Rotating Machinery Characteristics (Point Design B) . . . . 33

References . . . . . . . . . . . . . . . . 35

Table I - IIPF Parameters Common to Both Point Designs

(A and B)................. . . 38

Table II - LTPF Parameters for Point Design A

(Continuous Sinusoidal Waveform) . . . . . . . 39

Table III - LTPF Parameters for Point Design B

(Intermittent Trapezoidal Waveform). . . . . . 40

Figures . . . . . . . . . . . . . . . . . 41 


\title{
LTPF: A LINEAR THETA-PINCH NEUTRON SOURCE
}

\author{
William R. E11is \\ Los Alamos Scientific Laboratory \\ Los Alamos, NM 87544, U.S.A.
}

\begin{abstract}
The linear theta pinch is optimized with respect to maximum neutron current on a sample located between the discharge tube and the compression coil wall. Emphasis throughout is placed on physics and technology considerations which govern the choice of parameters. Technological demands are (hopefully) kept to a minimum. Two "point designs" are developed which are distinguished by their compressional magnetic field (i.e. coil current) waveforms: one is sinusoidal and continuous, the other trapezoidal and pulsed intermittently. Both point designs give an average neutron current of $\sim 5 \times 10^{13} \mathrm{n} / \mathrm{cm}^{2} / \mathrm{s}$. Both devices are characterized by short lengths ( $1 \mathrm{~m})$, rapid cycling $(2-30 \mathrm{kHz})$, and magnetic mirrors $(2-5: 1)$ at the ends. A crucial item is the porser supply, which is discussed in detail.
\end{abstract}

\section{INTRODUCTION}

In this paper the linear theta pinch is treated as a source of $14-\mathrm{MeV}$ neutrons, sometimes called a "FERF". The name FERF (for Fusion Engineering Research Facility) applies to CTR devices whose function is to duplicate, as realistically as possible, the radiation and stress environment of a nurlear fusion reactor core for purposes of component and material testing. A FERF facility is non-existant at present, but its need is generally recognized by the CTR community. In addition to providing a high-energy neutron source of appropriate spectrum and intensity, a FERF would aiso be expected to simulate the bremsstrahlung radiation, particle first-wall impingement, cyclic stress, high operating temperature, and other factors associated with an operational D-T power plant.

A reactor test facility, or FERF, of the above scope represents an ambitious goal, but it is also an important milestone on the road to fusion power. Without such a facility, the planned opera'ion of an Experimental Power Reactor (EPR) by the year 1992 [1] and the subsequent operation of a Demonstration Power Plant (DPP) by the year 2000 [1] would proceed without reasonable assurances regarding reactor material lifetimes, component interactions, and maintenance downtimes.

We will show that the linear theta-pinch FEKF (LTPF) has three important advantacos over some other proposed neutron sources: (1) the device can be 
designed to produce its maximum output of neutron current (for definitions of neutron transport terminology (flux, fluence, current, etc.), see Appendix Ij at machine lengths of the order of 1 meter; hence the unit size will be smal1, and costs should be low; (2) the linear-pinch is a krown and tested system at the sizes to be proposed for the LTPF, hence technology extrapolations can be kept to a minimum; (3) the theta pinch will prepare and confine an actual thenionuclear plasma, permitting various plasma physics effects (e.g. bremsstrahïung, particle-wall jnteractions) and engineering systerns (e.g. hydrogen-isotope fueling, heat removal) which may be impcrtant in fusion reactors to be tested.

The LTPF, by definizion, is designed to produce $14-\mathrm{MeV}$ neutrons. It does not require "energy-breakeven," as a reactor does, and in fact will be a prolific consumer of electrical power. The tritiun-breeding lithium blanket can be eliminated, if desired for simplicity, provided a bottle of tritium is available for fuel. (The tritiun consumption is in the one-gram-per-month range).

The basic philosophy followed throughout this study is that rapid development of the LTPF technology -- rapidly-cycled power supplies, sophisticated gas-handling systems, heat removal in enormous quantities, remote operation of a radioactive machine, etc. -- can best be accomplished if the LTPF has a minimum number of technical innovations over conventional theta pinches. Consequently this LTPF design resembles present-day thata-pinch experiments in many ways.

Finally, a word about optimization: the set of variables seiected here is not unique, but is important to the specific resulls obtained. The variables describe the theta pinch coil, the thermonuclear plasma, and the power supply; all three constituents are important in the cuerall design. They must be represented by a few key variables for the problem to be tractable.

In section II the theta-pinch geometry and the basic LTPF assumptions are introduced. In seclion III the LTP scaling laws are derived, and in section IV the LTPF is optimized for mavimum neutron current. Two specific point designs are develuped in section $V$. Power supplies are considered in section VI, and finally some conclusions are drawn in section VII. Three Appendices deal with neutronics definitions, the theory of theta-pinch heating as applied to the LTPF, ind more about piwer supplies and circuits.

\section{BRIEF DESCRIPTION OF THE LTPF}

\section{A. Geometry}

The basic geometry of the linear theta pinch is shown in Fig. 1. The compression coil, which may be either single-turn, as shown here, or multipleturn, carries a current $I$ in the azimithal (theta) direction, generating a straight uniform magnetic field 3 which radially confines a long uniform cylinder of high- $\beta$ D-T plasma. The maximum plasma density $n$ which can be confined at thermonuclear temperatires is in the $10^{16}-10^{17} \mathrm{~cm}^{-3}$ range, corresponding to a maximum magnetic field $\mathrm{E}_{\mathrm{o}}$ of a few hund zed $\mathrm{kG}$. The compression coil may require laminations, to reduce unwanted eddy currents (the skin effect), and a large cooling systein will be required, to remove the ohmic (joule) heat.

Figure 2 shows a pho tograph of an actual linear theta pinch device, the Scylla IV-3 experiment operated at LASL diring 1965-69. In this device the 
coil bore $\left(2 h_{2}\right)$ was $10 \mathrm{~cm}$, the length $\mathrm{L}$ was 3 meters, the maximum field $B_{0}$ $\sim 50 \mathrm{kG}$, the ion tensizy $\mathrm{n} \sim 2 \times 1016 \mathrm{~cm}^{-3}$, the ion temperature $\mathrm{T}_{1} \sim 1.4 \mathrm{keV}$, and the electron temperature $\Gamma_{e} \sim 0.4 \mathrm{keV} \mathrm{[2].} \mathrm{When} \mathrm{Scylla} \mathrm{IV} \mathrm{was} \mathrm{operated}$ as a l-meter device, the correspunding parameters were $B_{0} \sim 80 \mathrm{kG}$, n $3 \mathrm{x} 10^{16} \mathrm{~cm}^{-3}, T_{1} r 3.2 \mathrm{rieV}$, and $T_{\mathrm{e}} \sim 0.3 \mathrm{keV}$ (deuterium gas used in all cases) [2]. These paramiters are typical of linear theta-pinch operation without sefarate shock heating.

The ion temperature $\mathrm{I}_{1} \mathrm{can}$ be increased into the thermonuclear range ( $>5 \mathrm{keV}^{\text {) }}$ by several methods, incluting separate shock heating. Shock heating should be much easier to implement than some of the more exotic posstbilities, such as eleciron beam heating, Marshall-gun injection, etc., especially if the shock-heating electrlc field is kept small. Linear theta pinches are easier to heat tian toroilal pinches (either theta or 2 ), which require "fat" plasmas (large $/$ /b) for wall stabilization purposes, Consequently compressional heating, can be employed more successfully in linear devices. We will assume separate shock heating in the LTPF, but the shockheating requirements will be kept deliburately mild (applied Eij's $<1 \mathrm{kV} / \mathrm{cm}$ ).

The shock heating coil is shown in Fig. 3 positioned between the ceramic (or fused quartz) discharge tube and the compresion coil. The shock-heating coil is electrically insulated fom the iompression coil as shown.

Sample materials to be irraciated are located between the shock-heating coil and the discharge tube. Approxinately $1 \mathrm{~cm}$ of space is provided in the design for this purpose. Ports are provided in the compression coil to admit 14-MeV neutrons into the space bey ond the soil (see Fig. 1). Neutrons of degraded energy are also available outside the compression coil, having passed through the wall (typically $5-10 \mathrm{~cm}$ in thickness).

The LTPF is assumed to have no lithium blanket, altnough a blanket structure could of course be provided for meterial wiesting purposes, breeding ratio measurements, etc., if desired. The bianket would be located outside the ompression coil.

\section{B. Plasma Physics Assurotizns.}

We will assume a sharp-boundary MHD model for the piasma column with different electron and ion temperatures, $T_{e}$ and $T_{i}$, and make the reasonably good approximation for theta pirches, $B=1$ " The electron and ion temperatures and ion density are assumed to be constant after the start of the "burn" phase, and equal to the values attained at the end of the compressional heating phase. This implicitly assumes a low fractional burnup and negligible alpha-particle heating. In general, as the alpha particles are produced during a D-T burn (one alpha particle is produced per $14-\mathrm{MeV}$ neutron), they are thermalized $i=$ tise plasm : by the colder, more dense fuel ions. Concomitantly, the fuel ions are heated by the alpha particles. The net result is an expansion of the high- $\beta$ plasma against the confining magnetic field, with an associated increase in the plasma ion temperature and a decrease in the ion density. Computer calculacions by Oliphant [3], employing numerical solution of the Fokker-Planck equation using time-deperdent distribution functions, have shown alpha-particle heatirg and zuel-ion depletion to be negligible in all parameter ranges of interest for the LTPF (e.g. a burn of less than $500 \mu s$ duration in any practical magnetic field). Therefore the psasma temperature, density, and radius will be assumed constant during the LTPF burn, which simplifies the calculations. 


\section{Neutron Current Requirements}

Most D-T fusion reactor designs [4,5] 1 imit the acceptable first-wall loading due to uncollided $(14-\mathrm{MeV})$ neutrons, $\overline{\mathrm{I}}_{\mathrm{w}}$, to $\mathrm{i}-3 \mathrm{MW} / \mathrm{m}^{2}[6-9]$. Since each uncoliided neutron transports $14.06 \mathrm{MeV}\left(2.25 \times 10^{-12} \mathrm{~J}\right)$ of kinetic energy to the wall, the wall ioading is related to the time-averaged uncollided neutron current density $\langle\mathrm{J}\rangle$ by a constant:

$$
\Delta\rangle=4.44 \times 10^{13} \bar{I}_{\mathrm{w}} \mathrm{n} / \mathrm{cm}^{2} / \mathrm{s}
$$

for $\vec{I}_{w}$ in $M N / m^{2}$. Thus a wall-loading of $2 \mathrm{MW} / \mathrm{m}^{2}$ corresponds to a neutron current of $8.88 \times 10^{13} \mathrm{n} / \mathrm{cm}^{2} / \mathrm{s}$, and this $1 \mathrm{~s}$ roughly the value one would expect to encounter in a D-T fusion reactor. Ideally a FERF wiuld produce even higher neutron currents, e.g. $10^{15} \mathrm{n} / \mathrm{cm}^{2} / \mathrm{s}$, in order to ghorten the time required for substantial material damage effects over that for reactor component lifetimes (estimated at $\sim 1$ year).

It will be shown that neutron currents in excess of $5 \times 10^{13} \mathrm{n} / \mathrm{cm}^{2} / \mathrm{s}$ are difficult to generate in an LTPF. Neutron currents of $10^{13} \mathrm{n} / \mathrm{cm}^{2} / \mathrm{s}$ appear to be fairly readily achievable.

In order to increase the utility of the LTPF, and to reduce projected material-cesting times to a practical minimum, we will take as our primary design criterion the maximization of the neutron current $\langle J\rangle$.

\section{SCALING RELATIONS FOR THE LTPF}

\section{A. Parameterizing the Neutron Current} by $[10]$

For a D-T plasma with Maxwellian Ions, the fusion reaction rate is given

$$
\mathrm{R}=\mathrm{n}_{\mathrm{D}} \mathrm{n}_{\mathrm{T}} \overline{\sigma v}(\mathrm{~T}) \quad \text { reactions } / \mathrm{cm}^{3} / \mathrm{s} \text {, }
$$

where $\overline{\sigma v}(T)$ is the Maxwel1-zveraged fusion cross section, $T$ is the ion teinperature, and $n_{D}$ and $n_{T}$ are the ion densities for deuterium and tritium, respectively. For a $50 / 50 \mathrm{D}-\mathrm{T}$ mixture, $n_{D}=n_{T}=n / 2$, the number of neutrons produced per cm of plasma column in a burning pulse of duration $\tau_{b}$ sec is ( $a$ = plasma radius)

$$
\text { \# neutrons }=\frac{\pi}{4} a^{2} n^{2} \overline{\sigma v}(T) \tau_{b} \quad \mathrm{~cm}^{-3} \text {. }
$$

For pulsed operation with cycle time $\tau_{c}$ ( $\tau_{c}=$ number of seconds between successive burning pulses), the time-averaged uncollided neutron current density, $\langle J\rangle$, at the sample radius $b_{s}$ (see $1 \mathrm{fg} .3$ ) 1s obtained by dividing by $2 \pi b_{s} \tau_{c}$ :

$$
\langle\mathrm{J}\rangle=\frac{\mathrm{a}^{2} \mathrm{i}^{2} \overline{\sigma_{v}}(\mathrm{I})}{8 \mathrm{t}} \frac{\tau_{\mathrm{t}}}{\tau_{\mathrm{c}}} \quad \mathrm{n} / \mathrm{cm}^{2} / \mathrm{s}
$$

Our units are a and $b_{s}$ in $\mathrm{cm}, \mathrm{n}$ in $\mathrm{cm}^{-3}, \overline{\sigma v}(\mathrm{~T})$ in $\mathrm{cm}^{3} / \mathrm{s}$, and $\tau_{\mathrm{b}}$ and $\tau_{c}$ in seconds. In the interest of brevity wo will refer to $\langle J\rangle$ henceforth as 
the "neutron current."

Equation (4) is not in a useful form for maximizing $\langle J\rangle$, since $a, b_{s}$, $n_{\text {, }}$ $T, \tau_{b}$, and $\tau_{c}$ cannot all be specified independently. In addition to such obvious constraints as $b_{s}=a, T_{c}>T_{b}$, etc., more subtle constraints arise involving conflicting physics requirements, shock-heating considerations, strength-of-materials limitations, availability of electrical power, etc. Some of these constrairts are not apparent by inspection of Eq. (4).

The proper choice of independent variables in the LTPF problem is a crucial step, and a subjective one. In this and following sections we will systematically develop a parameterization and a set of design equations for the LTPF which have been found by trial-and-error to be the most useful. other parametezizations are certainly possjble, but the writer prefers the independent variables used $\vdots .:$ t:is study.

We wili need the foiluiving relations:

1. Plasma Pressure Balance. In SI units the pressure baiance relation is

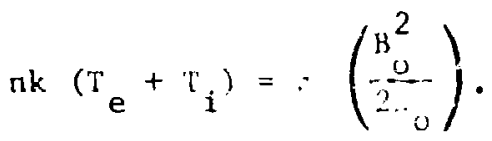

For a ratio of electron temperature to ion temperature equal to $\lambda\left(\mathrm{T}_{\mathrm{e}} / \mathrm{T}_{\mathrm{i}}=\right.$ $i \leq 1$ for theta pinches), and assuming $E=1$, the density can be written

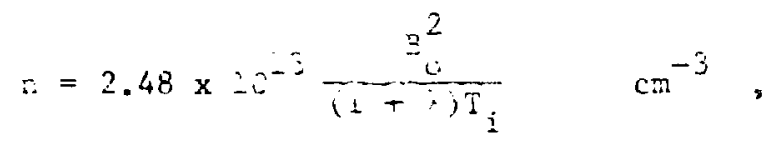

where $n$ is in $\mathrm{cm}^{-3}$ for $B_{0}$ in $k G$ and $T_{i}$ in $k e V$. For notational convenience we wili drop the subscript " $i$ " on the ion temperature, and the symbol $T$ wil? refer to the ion temperature in the remainder of this report.

2. Shock-Heating Requirements. Shock heating tollowed by adiabatic compression is the tradicional method of heating plasmas in theta pinches [11-13]. The theory of "separate" (the term "separate" as used here applies to a separate power supply) shock heating has been developed in detail elsewhere $[14,15]$. The theory has been modified to include unequal electron and ion temperatures in Appendix II. The resutt can be expressed in the following equation:

$$
E_{\theta}=0.244\left(\frac{1+\vdots}{2}\right)^{i / 2}\left(\frac{\mathrm{a}}{\mathrm{b}_{1}}\right)^{7 / 3} \mathrm{~B}_{\mathrm{o}} \mathrm{T}^{\mathrm{i} / 2}
$$

( $E_{\theta}$ in $\mathrm{kV} / \mathrm{cm}$ for $a, b_{1}$ in $\mathrm{cm}, B_{0}$ in $k G$, and $T$ in $k e V$ ), where $E_{\theta}$ is the electric field (applied at radius $b_{1}$ ), $B_{0}$ is the final magnetic compression field, $T$ is the final ion temperature (after compression), $a / b_{1}$ is the equilibrium compression ratio, and $\lambda=\mathrm{T}_{\mathrm{e}} / \mathrm{T}_{\mathbf{i}}$. Solvirg for the plasma radius $\Omega$ yields 


$$
a=1.83\left(\frac{2}{1+1}\right)^{3 / 14}\left(\frac{E_{\theta}}{B_{0}}\right)^{3 / 7} \frac{b_{1}}{T^{3 / 14}} \quad \mathrm{~cm}
$$

$(\mathrm{kV} / \mathrm{cm}, \mathrm{kG}, \mathrm{cm}, \mathrm{keV})$ in terms of the tube radius, temperature, applied fields.

3. End-Loss Time. Particle end-loss is an important effect in linear theta pinches, anc the shorter the device the shorter the useful confinement time for a given temperature. The mirimum plasma length is found by equating the required confinement tịe, $\tau_{b}$, to the characteristic end loss time, IEL. Using the definizions $\dot{N}=-N / \tau_{E L}$ and $\dot{N}=-2 \Gamma$, where $N$ is the total number of particles originally in the plasma and $\Gamma i s$ the rate at which particles ute lost from either end, the end loss time ${ }^{2} \mathrm{~L}$ can be written in the form [16!

$$
\tau_{E L}=\frac{L}{2}\left(\frac{m_{i}}{2 k T}\right)^{1 / 2}\left(2 \sqrt{\pi} n_{m}\right)
$$

where $L$ is the total length of the pinch, $m_{j}$ is the mass of an "average" $D-T$ ion ( $4.2 \times 10^{-27} 4 \mathrm{~kg} ;$, and $\eta_{\mathrm{m}}$ is a "toirror parameter" which gives the ratio of total particles incident on one end of the machire to particles lost from that. end. For a low- $B$ device without mirrors, $n_{m}=1$. If strong mirrors are applied, then $\eta_{m} \sim R$, where $R$ is the applied wirror ratin. In high- $\beta$ devices there is a self-mirroring effect even without applied mirrors. Several calculations of $\eta_{m}$ have been made in this case, and are reviewed in ref [16]. An analytic form, $\eta_{m}=2 R /(1+\sqrt{1-B})$, derived by Freldberg [17] for the case of a diffuse boundary plasma, gives slightly more optimistic results than numerical computations of $\eta_{m}[16]$. We will use Freidberg's analytic result in the form

$$
\eta_{\mathrm{m}}=\frac{2 \alpha R}{1+\sqrt{1-B}}
$$

where $\alpha$ is an empirical coefficient which serves two important functions: it allows Eq. (10) to be brought into line with experimentally-measured end-loss times ( $\alpha$ is typically 1/2); and it allows the machine length to be choser larger than the minimum value dictated by end-lcss considerations, if desired (i.e. choose $\alpha<1 ; 2$ ).

Substituting Eq. (11) into Eq. (10), letting $\tau_{E L}=\tau_{b}$ and $\beta=1$, yields the plasma length:

$$
L=7.75 \times 10^{6} \frac{\tau_{b^{1}} T^{1 / 2}}{\alpha R}
$$

( $L$ in cm for $\tau_{b}$ in seconds, $T$ in $\mathrm{keV}$ ).

4. D-T Fusion Cross-Section. The D-T fusion cross-section $\overline{\sigma v}(\mathrm{~T})$ is a function of ion temperature only. It has the experimental temperature dependence 


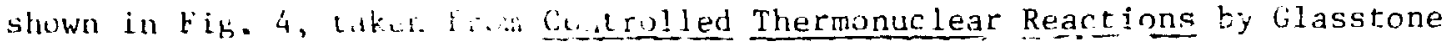

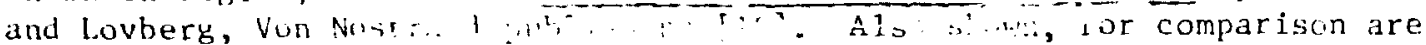

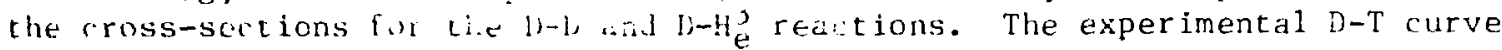
can be approximated by [10]

$$
\pi v(T)=\frac{3.68 \times 10^{-12}}{T^{2 / 3}} \exp \left(-\frac{19.94}{T^{2 / 3}}\right) \quad \mathrm{cm}^{3} / \mathrm{s}
$$

( $T$ in $\mathrm{keV}$ ). In the $5-10 \mathrm{keV}$ temperature range of interest to the LTPF (see below), a becter fit is sbtai aed if Eq. (13) is multiplied by a factor of 1.35. Thus we will a. is

$$
\overline{i v}(\mathrm{~T})=\frac{5.0 \times 10^{-12}}{\mathrm{~T}^{2 / 1}}-\mathrm{cm}\left(-\frac{19.94}{\mathrm{~T}^{1 / 3}}\right) \quad \mathrm{cm}^{3} / \mathrm{s} .
$$

5. power Supply Consijercions, Substituking Eqs. (6), (9), (12), and (14) into Eq. (4) eliminates .., a, T , and $\mathrm{GV}(T)$, respectively, yielding for the neutron current $\{12\}$,

$$
\begin{aligned}
\langle\mathrm{J}= & =4.15 \times 10^{7}\left(\frac{2}{1+\lambda}\right)^{17 / 7} \frac{\mathrm{aRb}_{1}^{2}}{\mathrm{~b}_{\mathrm{s}}} \frac{\mathrm{E}_{\theta}^{6 i 7} \mathrm{~B}_{\mathrm{o}}^{22 / 7}}{\tau_{\mathrm{c}}} \mathrm{L} \\
& \times\left\{\mathrm{T}^{-151 / 42} \exp \left(-\frac{19.94}{\mathrm{~T}^{1 / 3}}\right)\right\} \mathrm{n} / \mathrm{cm}^{2} / \mathrm{s} \quad
\end{aligned}
$$

Equation (15) shows the necessity of high-field operation for obtaining the highest values of neutron current; $\tau_{c}$ is also an obviously crucial parameter.

An example will serve to illustrate some points. Assume $B_{0}=300 \mathrm{kG}$, $\imath=1 / 2, R=1$ (no applied mirrors), $\lambda=1$ (equal electron and ion temperatures), $E_{0}=2 \mathrm{kV} / \mathrm{cm}$ (the design point for LASL's staged theta-pinch experiment), $b_{1}=10 \mathrm{~cm}$, and $b_{s}=11 \mathrm{~cm}$. The maximum value of $\langle J\rangle$ occurs for $\mathrm{T}=6.3 \mathrm{keV}$ (set $\partial(\langle\mathrm{J}\rangle) / \partial \mathrm{T}=0$ ). Assuming $\mathrm{T}=\dot{0} .3 \mathrm{keV}$, and requiring $\langle\mathrm{J}\rangle=$ $10^{14} \mathrm{n} / \mathrm{cm}^{2} / \mathrm{s}$ yields the linear relationship between length and cycle time,

$$
L=1.75 \times 10^{5} \tau_{C}(s) \quad \operatorname{cm} .
$$

Either L or 1 may be arbitrarily chosen, but not both. For example if $\tau_{c}=1 \mathrm{~s}, \mathrm{~L}=1750^{\mathrm{c}} \mathrm{m}$; if $\tau_{c}=1 \mathrm{~ms}, \mathrm{~L}=1.75 \mathrm{~m}$; elc. Let us denote the $\mathrm{L}=$ $1.75 \mathrm{~km}$ case as the "long" case and the $\mathrm{L}=1.75 \mathrm{~m}$ case as the "short" case for purposes of illustration. Some important principles can be daduccd from these two cases.

The magnetic energy in the coil bore, $E_{M}$ ( 1 -glecting for the present the penetration of field into the coil wall), is given by 


$$
E_{M}=\left(\pi b_{2}^{2}\right)\left(\frac{B_{o}^{2}}{2 \mu_{o}}\right) L
$$

in SI units, or

$$
E_{M}=1.25 \times 10^{-8} \mathrm{~b}_{2}^{2} \mathrm{~B}_{\mathrm{o}}^{2} \mathrm{~L} \quad \mathrm{MJ}
$$

$\left(B_{0}\right.$ in $k G$ and $b_{2}$ and $L$ in $\mathrm{cm}$ ). Substituting $b_{2}=13 \mathrm{~cm}, B_{o}=300 \mathrm{kG}$, and $i=1.75 \times 10^{5} \mathrm{~cm}$ ( $t$ he "long" case) yields $E_{M}=33 \mathrm{GJ}$. The steady-state power transfer is $E_{M} / \tau_{c}=33 \mathrm{GW}$.

In the "sho:t" case, $E_{M}$ is reduced by a factor of one thousand, to $33 \mathrm{MJ}$. The steady-state power transfer, $E_{M} / \tau_{c}$, is still $33 \mathrm{GW}$, however, since the transfer time $\tau_{c}$ is reduced in exact proportion to the length $\mathrm{L}$, and $\mathrm{L}$ determines the amount of energy transferred. Also, if a certain fraction of the energy is lost per pulse in jolle heating, say $10 \%$, then in either the "short" case or the "long" case the same amount of power is dissipated in the circuit. For a $10 \%$ loss, that make-up power is $3.3 \mathrm{GW}$ in our example.

The following general observations can be made: (1) The power required by the LTPF is independent of the particular combination of length and cycle time chosen, but if the "short" mode (rapid cycling, short length) is chosen the energy requirement is much reduced, and thereby, presumable, the capital cost. (2) The dissipated power (i.e. the power consumed from the line) is potentially so large for neutron currents of $10^{14} \mathrm{n} / \mathrm{cs}: " / \mathrm{s}$ that very careful consideration must be given to reducing the dissipated power per unit of neutron current. (3) Heat removal problems will tand to be severe, particularly in short coils. Since the total joule loss in the circuit is fixed (for a given $\langle J\rangle$ and $Q$ ), shorter coils will have greater heat densities.

These considerations lead us to identify the power consumption and the circuit quality factor as primary variables in the LTPF problem. Predictions of neutron current can be examined realistically only when power-supply characteristics are folded into the scaling equations.

B. Deriving the Scaling Equations

Define a quality factor "Q" for the circuit such that

$$
Q=\frac{E_{M}}{E_{J}}
$$

where $E_{M}$ is the energy transferred into the compression coil per cycle, and $E_{J}$ is the energy lost per cycle as joule heat. If $P$ is defined as the steady-state average power loss in the circuit, then

$$
P=\frac{E_{J}}{\tau_{c}},
$$

and from Eqs. (19) and (20), 


$$
Q=\frac{E_{M}}{P_{\tau}}
$$

Eiminating $E_{M}$ between Eqs. (21) and (18) yields the machine length in terms of the parameter QP:

$$
\mathrm{L}=8.00 \times 10^{7} \frac{(\mathrm{QP}) \mathrm{T}_{\mathrm{c}}}{\mathrm{b}_{2}^{2} \mathrm{~B}_{\mathrm{o}}^{2}} \quad \mathrm{~cm}
$$

( $L$ in $c m$ for $Q P$ in $M W, T_{c}$ in seconds, $b_{2}$ in $c m$, and $B_{o}$ in $k G$ ).

The usefulness of this formulation is that nearly all of the important LTPF equations can be formulated in terms of $Q P$, and both $Q$ and $P$ are relatively easy to estimate in a practical circuit.

Elimirating $L$ from Eqs. (22) and (14) yields

$$
\frac{\tau_{b}}{\tau_{c}}=10.3 \frac{\alpha R(Q P)}{b_{2}^{2} B_{0}^{2} T^{1 / 4}}
$$

for the duty factor in terms of $Q P$.

The quantity $\tau_{c} / \tau_{b}$ is an important design parameter which we will take as an independen: variable, along with QP. Rearranging Eq. (23) yields the magnetic field,

$$
B_{0}=3.21 \frac{\left[\alpha R(Q P)\left(\tau_{c} / \tau_{b}\right)\right]^{1 / 2}}{b_{2} T^{1 / 4}} \quad k G
$$

( $B_{0}$ in $k G$ for $Q P$ in $M W, b_{0}$ in $\mathrm{cm}, T$ in $\mathrm{keV}$ ).

If the applied mirror ratio $R$ is greater than unity, the maximum field, $\mathrm{B}_{\max }$, occurs in the mirror throat with magnitude $B_{\max }=R B_{0}$. Hence, from Eq. (24),

$$
\mathrm{B}_{\max }=3.21 \frac{\left[\alpha \mathrm{R}^{3}(\mathrm{QP})\left(\tau / \mathrm{\tau}_{\mathrm{b}}\right)\right]^{1 / 2}}{\mathrm{~b}_{2} \mathrm{~T}^{1 / 4}} \mathrm{kG}
$$

Substituting $B_{0}$ from Eq. (24) and L from Eq. (22) into Eq. (15) for 〈J〉 yields the neutron current:

$\left.\langle\mathrm{J}\rangle=1.26 \times 10^{16}\left(\frac{2}{1+\lambda}\right)^{\frac{17}{7}}[\mathrm{aR}(\mathrm{QP})]^{\frac{11}{7}} \frac{\mathrm{b}_{1}^{2} \mathrm{E}_{\theta}^{\frac{6}{7}}\left(\tau_{\mathrm{c}} / \tau_{\mathrm{b}}\right)^{\frac{4}{7}}}{\mathrm{~b}_{2}^{\frac{22}{7}} \mathrm{~b}_{\mathrm{s}}} \mid \mathrm{x}^{-\frac{163}{42}} \exp \left(-\frac{19.94}{\mathrm{~T}^{1 / 3}}\right)\right\} \mathrm{n} / \mathrm{cm}^{2} / \mathrm{s}$. 
Combining Eqs. (9) and (24) yields the plasma radius:

$a=1.11\left(\frac{2}{1+\lambda}\right)^{3 / 14} \frac{1}{r^{3 / 28}} \frac{b_{1} b_{2}^{3 / 7} E_{\theta}^{3 / 7}}{\left[\alpha R(Q P)\left(\tau_{c} / \tau_{b}\right)\right]^{3 / 14}} \quad \mathrm{~cm}$

The gyroradius (or Larmor radius) of a charged particle having temperature $T$ and charge $q$ in a magnetic field $B_{0}$ is given by

$$
r_{L}=\frac{\left(2 m_{i} k T\right)^{1 / 2}}{q_{0}}
$$

in SI units. In a D-T plasma with a given ion temperature, the largest gyroradius is associated with tritions. Substituting for the trition mass $\left(\mathrm{m}_{\mathrm{T}}=\right.$ $\left.5.006 \times 10^{-? 7} \mathrm{~kg}\right)$ and proton charge $\left(\mathrm{q}=1.602 \times 10^{-19} \mathrm{C}\right)$ yields

$$
r_{L}=7.24 \frac{T^{1 / 2}}{B_{0}} \quad \mathrm{~cm}
$$

( $r_{\mathrm{L}}$ in $\mathrm{cm}$ for $\mathrm{T}$ in $\mathrm{keV}, \mathrm{B}_{\mathrm{o}}$ in $\mathrm{kG}$ ). Combining Eqs. (24), (27), and (29) yields the ratio of plasma radius to gyroradius in our variables:

$$
\frac{a}{r_{L}}=0.492\left(\frac{2}{1+\lambda}\right)^{3 / 14} \frac{b_{1} E_{\theta}^{3 / 7}}{b_{2}^{4 / 7} T^{6 / 7}}\left[\alpha R(Q P)\left(\tau_{c} / \tau_{b}\right)\right]^{2 / 7}
$$

The criterion $a / r_{L} \geq 1$ must be satisfied at all times for physical feasibility [18].

The Lavson parameter nt furnishes another plasma physics criterion and provides a useful quantitative measure of the difficulty of the proposed confinement system. From Eqs. (6) and (24), the ion density is

$$
\mathrm{n}=1.28 \times 10^{14}\left(\frac{2}{1+\lambda}\right) \frac{\alpha \mathrm{R}(\mathrm{QP})\left(\tau_{\mathrm{c}} / \tau_{\mathrm{b}}\right)}{\mathrm{b}_{2}^{2} \mathrm{~T}^{3 / 2}} \quad \mathrm{~cm}^{-3}
$$

Multiplying by $\tau_{b}$ yields

$$
n \tau_{b}=1.28 \times 10^{14}\left(\frac{2}{1+\lambda}\right) \frac{\alpha R(Q P) \tau_{c}}{b_{2}^{2} T^{3 / 2}} \quad \mathrm{~cm}^{-3}-\mathrm{s} .
$$

These relationships form the basic set of scaling equations for the LTPF. For convenience they are collected below: 


$$
\begin{aligned}
& \langle J\rangle=1.26 \times 10^{16}\left(\frac{2}{1+\lambda}\right)^{17 / 7}[\alpha R(Q P)]^{11 / 7} \frac{{ }_{{ }_{1}^{2} E_{\theta}^{6 / 7}\left(\tau_{c} / \tau_{b}\right)}}{b_{2}{ }^{22 / 7_{b}}} \\
& \mathrm{x}\left\{\mathrm{T}^{-163 / 42} \exp \left(-\frac{19.94}{\mathrm{~T}^{1 / 3}}\right)\right\} \quad \mathrm{n} / \mathrm{cm}^{2} / \mathrm{s} \\
& \mathrm{B}_{0}=3.21 \frac{\left[\alpha \mathrm{R}(\mathrm{QP})\left(\tau_{c} / \tau_{b}\right)\right]^{1 / 2}}{\mathrm{~b}_{2} \mathrm{~T}^{1 / 4}} \mathrm{kG} \\
& B_{\text {max }}=R B_{0}=3.21 \frac{\left[a R^{3}(Q P)\left(\tau_{c} / \tau_{b}\right)\right]^{1 / 2}}{b_{2} T^{1 / 4}} \quad k G \\
& \mathrm{E}_{\mathrm{M}}=(\mathrm{QP}) \tau_{\mathrm{c}} \quad \mathrm{MJ} \\
& L=7.75 \times 1.0^{6} \frac{\mathrm{T}^{1 / 2} \tau_{b}}{\alpha R} \quad \mathrm{~cm}
\end{aligned}
$$

$$
\begin{aligned}
& \frac{a}{r_{L}}=0.492\left(\frac{2}{1+\lambda}\right)^{3 / 14} \frac{b_{1} E_{\theta}^{3 / 7}}{b_{2}^{4 / 7} T^{6 / 7}}\left[\alpha R(Q P)\left(\tau_{c} / \tau_{b}\right)\right]^{2 / 7} \\
& n=1.28 \times 10^{1.4}\left(\frac{2}{1+\lambda}\right) \frac{\alpha R(Q P)\left(\tau_{c} / \tau_{b}\right)}{b_{2}^{2} T^{3 / 2}} \mathrm{~cm}^{-3} \\
& n \tau_{b}=1.28 \times 10^{14}\left(\frac{2}{1+\lambda}\right) \frac{\alpha R(Q P) \tau}{b_{2}^{2} T^{3 / 2}} \mathrm{~cm}^{-3}-\mathrm{s}
\end{aligned}
$$

$\left(\mathrm{b}_{1}, \mathrm{~b}_{2}, \mathrm{~b}_{\mathrm{s}}\right.$ in $\mathrm{cm}, \mathrm{E}_{\theta}$ in $\mathrm{kV} / \mathrm{cm}, \mathrm{T}$ in $\mathrm{keV}, \mathrm{P}$ in $\mathrm{MW}, \tau_{\mathrm{b}}$ and $\tau$ in $s, \alpha, \mathrm{R}$, and $\mathrm{Q}$ dimensionless). 
We seek to maximize the neutron current, Eq. (33a), by optimizing the parameters $\alpha, R, Q P, T$, etr., subjest to reasonable plasma physics and engineering assumptions, and subjert to the constraint that ali the other scaling relations in Eq. (33) Ehould give reasonable results. The independent parameters in Eq. (33) have been selected to permit just this type of optimization approach.

\section{A. Optimum Ion Temperature}

The dependence of $\langle\mathrm{J}\rangle$ on the ion terperature is the bracketed expression in Eq. (33a), which we denoce as F(T):

$$
F(T)=T^{-163 / 42} \exp \left(-\frac{19.94}{T^{1 / 3}}\right)
$$

The function $F(T)$ is plotted in Fig. 5. The broad maximum is $\sim 2 \mathrm{keV}$ in width, and the temperature at the peak, found by setting $\partial F / \partial T=0$, is 5.0 keV. The maximum neutron current will thus occur, other things being equal, when the ion temperature is $5.0 \mathrm{keV}$, although small departures ( $\sim 1 \mathrm{keV}$ ) in either direction will produce neglible decreases in the neutron current. For self-consistency it will be necessary to show that the other quantities in Eq. (33) are not adversely affected by this choice of temperature; it will become apparent later that this condition is satisfied. Thus we choose $\mathrm{T}=5.0 \mathrm{keV}$.

\section{B. Optimum Coil and Tube Dimensions}

The dependence of $\langle\mathrm{J}\rangle$ in $\mathrm{Eq}$. (33a) on internal radius dimensions is given by

$$
G(b)=\frac{b_{1}^{2}}{b_{s} b_{2}^{22 / 7}}
$$

(see Fig. 3). It is important that the coil radius $b_{2}$ be kept as small as possible (note the $22 / 7$ power dependence). The coil radius $b_{2}$ exceeds the tube radius $b_{1}$ by an amount $\Delta$ (Fig. 3),

$$
\mathrm{b}_{2}-\mathrm{b}_{1}=\Delta
$$

and $\Delta$ should also be kept as small as possible since it represents wasted magnetic volume; note that $\langle J\rangle$ scales approximately as $1 /\left(1+\Delta / b_{1}\right)^{22 / 7}$. The space $\Delta$ must accomodate the wall of the discharge tube, the sample to be irradiated, the shock-heating coil, and any necessary electrical insulation. A reasonable conjecture is that $\Delta$ will be about $2 \mathrm{~cm}$.

The radius $b_{s}$ defining the sample location may be written $b_{s}=b_{1}+\varepsilon$, where $\varepsilon$ is small compared to $b_{1}$. If we make the further assumption that $\varepsilon$ is small compared to $\Delta$ (discharge tubes have thin walls), thes the optimum tube radius, found by setting $\partial G / \partial b_{1}=0$, is 


$$
\left(b_{1}\right)_{\text {opt }} \sim \frac{\Delta}{22 / 7-1}=0.47 \Delta
$$

For $\Delta=2 \mathrm{~cm}$, therefore, $\left(b_{1}\right)_{o p t}=0.93 \mathrm{~cm}$ and $b_{2}=2.93 \mathrm{~cm}$. These values are unfortunately not realistic for efficient shock heating in view of the measured sheath widths of 1-2 cm in typical theta pinches [19]. In the Scylla IV-1 theta pinch, which had a tube radius of $4.4 \mathrm{~cm}$, the measured ion temperature was $>3 \mathrm{keV}$ ( $c \bar{f}$ section iII and ref [20]). A choice of $b_{1}=5 \mathrm{~cm}$ $\left(b_{2}=7 \mathrm{~cm}\right)$ would therefore seem to assure efficient shock heating in the LTPF. If we further assume that the test sample radius $b_{S}$ is $0.5 \mathrm{~cm}$ greater than $b_{1}$, we arrive at:

$$
\begin{aligned}
& \Delta=2 \mathrm{~cm} \\
& \mathrm{~b}_{1}=5 \mathrm{~cm} \\
& \mathrm{~b}_{\mathrm{s}}=5.5 \mathrm{~cm} \\
& \mathrm{~b}_{2}=7 \mathrm{~cm}
\end{aligned}
$$

\section{Optimum $E_{\theta}$}

The shock-heating electric field $E_{\theta}$ will be taken as $1.0 \mathrm{kV} / \mathrm{cm}$ (toial). In practice a fraction of $E_{6}$ (which can be a substantial fraction in the case of LTPF) will be generated by the $d B / d t$ of the magnetic compression field, $B(t)$ (see discussion in Appendix III).

The value of $1.0 \mathrm{kV} / \mathrm{cm}$ may be compared with $0.51 \mathrm{kV} / \mathrm{cm}$ measured in the Scyllac 5-meter sector experiment [21], $0.70 \mathrm{kV} / \mathrm{cm}$ measured in the Scy.lla I-B theta pinch [19], arc $1.1 \mathrm{kV} / \mathrm{cm}$ measured in the Scylla IV-1 device [20]; in each of these cases $E_{\theta}$ was produced by the primary capacitor bank (no separate shock heating). Experiments with separate shock heating have traditionally produced higher fields $(2-3 \mathrm{kV} / \mathrm{cm})[13,22,23]$. The voltage at the shock coil radius $b_{S_{r}}$ is giver. $3 y\left(b_{S H} / b_{1}\right)\left(2 \pi b_{S H}\right) E_{\theta}=53 \mathrm{kV}$ for $b_{S H}=6.5 \mathrm{~cm}$. The stored energy $i_{i n} i t s$ shock-heating circuit is small ( $1 \%$ compared to the compression circtit), and we will neglect it.

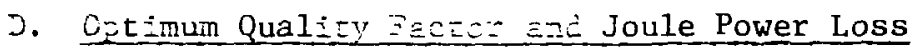

Since $\langle J\rangle$ in EG. (33a) scales asi $(Q P)^{11 / 7}$, both $Q$ and $P$ should be chosen as large as possibie. The maximum realistic Q value for the circuit will depend in detail on the power supply (see discussions in section VI and Appendix III), but in ary case will probably be much less than 100 . A measured circuit $Q$ of $\sim 20 \quad 5 \%$ decrement per cycle) was obtained by the Culham Group in a dynamic stabilization experiment on a theta pinch, using special high-Q Toby Deutschmann capecitors [24]. For present purposes we will assume an overall $Q$ of 15 for the LTPF.

The maximum amount of power $P$ which can be taken from the line depends on the availability and cost of the power, and the difficulty of removing joule heat from the compression coil, where most of $P$ will be dissipated. To address the first point, the Paducah gaseous diffusion plant for uranium enrichment in Kenclicky, one of the largest power consumers in the count:y, uses $2550 \mathrm{MW}$ at full capacity [25]. The LTPF will have to get by on much less. The cruciai inication is probably the maximun tolerable heat load in the coil. 
For purposes of illustration assume a coil length $L$ of 1.5 meters, a coil radius $b_{2}$ of $7 \mathrm{~cm}$, and a coil thickness of $9 \mathrm{~cm}$; the corresponding volume of metal is $\sim 10^{5} \mathrm{~cm}^{3}$. Assuming an optimistic tolerable heat load of $3 \mathrm{~kW} / \mathrm{cm}^{3}[26]$, the maximum tole:rable power loss is $10^{5} \times 3 \times 10^{-3}=300 \mathrm{MW}$. For purposes of this study we will assume $P=300 \mathrm{MW}$. The power supply must therefore be capable of handling $Q P=4500$ MVA, of which a fraction $Q^{-1}$, or $7 \%$, is lost per cycle.

\section{E. Optimum End-Loss Parameter}

The quantity $\alpha$ [see Eqs. (11) and (12)] is an empirical end-loss coefficient with a measured value of $\sim 0.5$ in linear Scyllac end-loss experiments [2]. Since $\langle\mathrm{J}\rangle$ in $\mathrm{Eq}$. (33a) scales as $\alpha^{11 / 7}$, $\alpha$ should be chosen as large as possible. [Note that if the length of the compression coil, $L$, is increased beyond its minimum required value (i.e. if $\alpha$ is articicially assigned values (0.5), 〈J> will decrease]. We will assume $\alpha=0.5$.

The remeining parameters in Eq. (33a) ( $\left.\lambda, R, \tau_{-} / \tau_{b}, \tau_{c}\right)$ caniot be specified without knowledge of the $B(t)$ waveform, which $i s$ the basis for the two point designs developed in the next section.

Substituting $\mathrm{T}=5.0 \mathrm{keV}, \mathrm{b}_{1}=5.0 \mathrm{~cm}, \mathrm{~b}_{\mathrm{s}}=5.5 \mathrm{~cm}, \mathrm{~b}_{2}=7.0 \mathrm{~cm}, \mathrm{E}_{\theta}=$ $1 \mathrm{kV} / \mathrm{cm}, \mathrm{Q}=15, \mathrm{P}=300 \mathrm{MW}$, and $\alpha=0.5$ into $\mathrm{Eq}$. (33) yields the following LTPF scaling equations "optimized" for maximum neutron current:

$$
\begin{aligned}
& \langle\mathrm{J}\rangle=3.91 \times 10^{11}\left(\frac{2}{1+\lambda}\right)^{17 / 7} \mathrm{R}^{11 / 7}\left(\tau_{\mathrm{c}} / \tau_{\mathrm{b}}\right)^{4 / 7} \mathrm{n} / \mathrm{cm}^{2} / \mathrm{s} \\
& B_{o}=14.6 \mathrm{R}^{1 / 2}\left(\tau_{c} / \tau_{b}\right)^{1 / 2} \quad \mathrm{kG} \\
& \mathrm{B}_{\max }=14.6 \mathrm{R}^{3 / 2}\left(\tau_{c} / \tau_{\mathrm{b}}\right)^{1 / 2} \quad \mathrm{kG} \\
& E_{M}=4500 \tau_{c} \quad M J \\
& L=3.46 \times 10^{7} \frac{\tau_{b}}{R} \quad \mathrm{~cm} \\
& a=2.06\left(\frac{2}{1+\lambda}\right)^{3 / 14} \frac{1}{\left[R\left(\tau_{c} / \tau_{b}\right)\right]^{3 / 14}} \mathrm{~cm} \\
& \frac{\mathrm{a}}{\mathrm{r}_{\mathrm{L}}}=1.85\left(\frac{2}{1+\lambda}\right)^{3 / 14}\left[R\left(\tau_{c} / \tau_{b}\right)\right]^{2 / 7} \\
& \mathrm{n}=5.23 \times 10^{14}\left(\frac{2}{1+\lambda}\right) \mathrm{R}\left(\tau_{c} / \tau_{\mathrm{b}}\right) \quad \mathrm{cm}^{-3}
\end{aligned}
$$




$$
\mathrm{n} \tau_{b}=5.23 \times 10^{14}\left(\frac{2}{1+\lambda}\right) \mathrm{R} \tau_{c} \quad \mathrm{~cm}^{-3} \cdot \mathrm{s}
$$

None of the scaling equations, at this point, yield physically unreasonable results. In particular, since $\lambda=T_{e} / T_{i} \leq 1$ in a theta pinch, and both the mirror ratio $R$ and duty factor $\tau_{c} / \tau_{b}$ are $\geq 1$ by definition, then $a / r_{L} \geq 1.85$ from Eq. $(39 \mathrm{~g})$, and the gyroradius criterion $a / r_{L} \geq 1$ is satisfied for any possible choice of the remainir four parameters.

Ultimate magnetic field strengths will be discussed in section $V . A$, where $300 \mathrm{kG}$ is arbitrarily chosen for the upper limit in both point designs. This and other UTPF parameters which are common to both point designs are given for reference in Table $I$.

\section{TWO LTPF POINT DESIGNS}

The parameters remaining to be specified in Eq. (39) for the LTPF scaling relations are the ratio of electron to ion temperature $\lambda$, the applied mirror ratio $R$, the duty factor $\tau_{c} / \tau_{b}$, and the cycle time $\tau_{c}$. The ratio of electron to ion temperature depends on thermal conduction to the ends of the device, and hence on the plasma density $n$ and length $L$, both of which depend on $R, \tau_{c} / \tau_{b}$, and $\tau_{c}$ (or $\tau_{p}$ ) [Eq. (39)].

In order to deal with these variables, we must consider specific coilcurrent (i.e. magnetic field) waveforms. A variety of waveforms are ( in principle) available from the power supply. We will begin by considering tie simplest class of wavefonis, sinusoids, as the basis for Point Design A. ir rapezoidal waveforms will be considered in Point Design $B$.

The point designs presented here are preliminary and certainly incomplete. Extensive engineering studies will be necessary to determine whether these designs are truly feasible. The main purpose at this time is to illustrate salient design features, identify important problem areas, and define parameter spaces where the LTPF is most likely to operate.

\section{A. Point Design A (Regular Sinusoidal Waveform)}

Two important features of sinusoid wavetorms are (1) their relative ease of ganeration (e.g. by a ringing capacitor bank) and (2) their relatively slow risetimes (a sine wave is essentially all "risetime", with zero timeduration at the peak). This last point has important consequences for plasma end-loss during the compressional heating phase of the discharge.

A variety of sinusoids are possible, such as the two examples shown in Fig. 6. Figure 6 a shows a "simple" sinuso:d,

$$
B(t)=B_{0} \sin (\omega t)
$$

and Fig. 6b shows a sinusoid superimposed on a steady D.C. bias field cf magnitude $\mathrm{B}_{\mathrm{o}} / 2$ :

$$
B(t)=B_{0}\left[\frac{1+\sin (\omega t)}{2}\right] \text {. }
$$


Note that the presence of the bias field reduces the cycle rate by a factor of 2 for the same angular frequency $\omega$, which can be a disadvantage in terms of $\langle\mathrm{J}\rangle$. An advantage, in principle at least, is that the D.C. component of field, being steady, might be generated by an external superconducting (solenoid) magnet which would involve no joule losses (but non-zero refrigeration losses).

The end-loss problem may be stated as follows. The plasma end-loss calculation, Eqs. (10)-(12), assumes a uniform plasma column of ion temperature $T$. This is equivalent to neglecting the heating phase of the pinch, during which $T$ is increasing, compared to the burning phase, when $T$ is ajsumed constant. In order for the end-loss calculations to be valid, therefore, the plasma must reach its operating temperature ( $5 \mathrm{keV}$ in this case) in a reasonable fraction of the sine-wave quarter-cycle. If the burn starts too soon, $T$ will not be constanc at $5 \mathrm{keV}$ during the burn due tc the concinuing compression. If the burn starts too late, much of the plasma will escape at high temperature before neutron production begins and the assumed icn density will be coo large.

Define the "risetime", $\tau_{r}$, as the time to the start of the burn (5 keV), as shown in Fig. 6, and not as the time to peak field. Then

$$
2 \tau_{\mathbf{r}}=\tau_{\mathbf{c}}-\tau_{\mathbf{b}}
$$

Solving for the duty factor $\tau_{c} / \tau_{b}$ yields

$$
\frac{\tau_{c}^{c}}{\tau_{b}}=1+2\left(\frac{\tau_{r}}{\tau_{b}}\right) \text {. }
$$

If we take into ac -ount the fact that $T$ is, on the average, substantially lower during $\tau_{r}$ than during $\tau_{p}$, then negligible plasma end-loss during $\tau_{r}$, compared to $\tau_{b}$, requires roughly that $\tau_{r} \lesssim \tau_{b}$. Equation (43) then yields

$$
\frac{\tau_{c}}{\tau_{b}} \lesssim 3
$$

Since $\langle J\rangle$ scales as $\left(\tau_{c} / \tau_{b}\right)^{4 / 7}$ [Eq. (39a)], the constraint in Eq. (44) is a serious matter.

Substituting $\tau_{c} / \tau_{b}=3$ into Eq. (39a) yields

$$
\langle\mathrm{J}\rangle=7.33 \times 10^{11}\left(\frac{2}{1+\lambda}\right)^{17 / 7} \mathrm{R}^{11 / 7} \mathrm{n} / \mathrm{cm}^{2} / \mathrm{s} .
$$

Noting that $0<\lambda \leq 1$ for a theta pinch, it is clear that very strong mirrors are required $(R>\rangle, 1)$ if $\langle J\rangle$ is to even approach values of $10^{14} \mathrm{n} / \mathrm{cm}^{2} / \mathrm{s}$.

The maximum acceptable mirror ratio is determined by the maximum acceptable magnetic field in the mirror throat. From Eq. (39c) this mirror field is given by 


$$
\mathrm{B}_{\max }=25.3 \mathrm{R}^{3 / 2} \quad \mathrm{kG}
$$

for $\tau_{c} / \tau_{b}=3$. Figure 7 shows the yield points of some possible coil materials plotted as a function of the magnetic field strength [18]. The corresponding magnetic pressure (ordinate of Fig. 7) is given by [12]

$$
\mathrm{F}_{\mathrm{m}}=0.588 \mathrm{~B}^{2} \quad \mathrm{psi}
$$

for $B$ in $\mathrm{kG}$. If we assume $B_{\max }=300 \mathrm{kG}\left(\mathrm{P}_{\mathrm{m}}=53,000 \mathrm{fsi}\right)$, then from Eq. (46), $R=5.2$. The magnetic field in the unmirrored central region is $\mathrm{B}_{0}=$ $57.7 \mathrm{kG}$, from Eq. (39b). These numbers may be compared with the linear Scyllac experimental mirror values [2], $B_{0} \sim 60 \mathrm{kG}, \mathrm{R} \sim 2.5-3, \mathrm{~B}_{\max }=250 \mathrm{kG}$ (maximum test value) [27].

Strong mirrors can induce $m=1$ instabilities in a theta-pinch plasma [2], and the question arises whether the intended thermonuclear burn in the LTPF can be completed in the available time if the plasma is unstable. The prospects for a successful confinement are obviously enhanced if the burn time (and hence the cycle time) is made very short.

An inspection of Eq. (39) shows that if the cycle time $\tau_{c}$ is chosen as short as possible, the machine length $L$, magnetic energy $E_{M}$, and Lawson parameter $n \tau_{b}$ are all reduced to their minimum practical values. This circumstance has its roots in physics considerations but here is a consequence of our particular choice of parameters.

A lower limit on $\tau_{c}$ is set by another technological constraint, namely the high voltages associated with rapidly-rising magnetic fields. As a compromise, and also to take advantage of well-known theta-pinch operating regimes, we will assume $\tau_{c}=30 \mu \mathrm{s}$, and hence $\tau_{b}=10 \mu \mathrm{s}$.

The remaining parameter in Eq. (39) is $\lambda$. Substituting $\tau_{b}=10 \mu \mathrm{s}$ and $\mathrm{R}=5.2$ into Eq. ( $39 \mathrm{e}$ ) yields the machine length $\mathrm{L}$ as $66.5 \mathrm{~cm}$, excluding mirrors. In short machines such as this the ratio of electron to ion temperature can be quite low, which is a distinct advantage for generating large neutron currents. Basically this occurs because pressure balance (for a given $B_{0}$ ) can be satisfied at higher ion densities than if electrons and ions had equal temperatures.

We can estimate the electron temperature in a theta pinch from a model by Morse $[2,28]$, who assumes a balance between heating from the ions and cooling by thermal conduction to the ends. In our units his equation (8) is

$$
T_{e}=1.08 \times 10^{-8}\left(\frac{T_{i} n^{2} L^{2}}{A_{i}}\right)^{1 / 5} \quad \mathrm{keV}
$$

Here ${ }^{n} i$ is the ion temperature in $\mathrm{keV}, \mathrm{n}$ is the ion density in $\mathrm{cm}^{-3}$, $L$ is the macinine length in $\mathrm{cm}, A_{i}$ is the atomic weight $(=2.5$ for $D-T)$, and we have assumed $\ln \Lambda=13$. In order to evaluate Eq. (48) we must know the dens:ty $n$, which depends on $\lambda$ [Eq. (39h)], which in turn depends on $T_{e}$. However, based on past experience with short theta pinches, we may begin by estimating $\mathrm{T}_{\mathrm{e}} \sim$ $250 \mathrm{eV}$ (1.e. $\lambda=0.05$ for $T_{i}=5.0 \mathrm{keV}$ ), and start an 1teration. It is 
helpful to re-write $\mathrm{Eq}$. (48) as

$$
\lambda=\frac{T_{e}}{T_{i}}=1.08 \times 10^{-8}\left(\frac{n^{2} L^{2}}{A_{i} T_{i}^{4}}\right)^{1 / 5}
$$

Substituting $\lambda=0.05$ into Eq. $(39 \mathrm{~h})$ gives $\mathrm{n}=1.55 \times 10^{16}$, and thus $\lambda \simeq$ 0.0398 from Eq. (49). This new value for $\lambda$ is substituted into $\mathrm{Eq}$. ( $39 \mathrm{~h}$ ), and after several iterations we obtain $\lambda=0.040$, corresponding to an electron te " perature of $200 \mathrm{eV}$.

Substituting $\tau_{c} / \tau_{b}=3, R=5.2, \tau_{c}=30 \mu \mathrm{s}, \tau_{b}=10 \mu \mathrm{s}$, and $\lambda=0.040$ into Eq. (39) yields the "Point Design A" parameters given in Table II. Various neutronics quantities of interest are also listed (see Appendix I for definitions).

Note that, because of its small $\tau_{c} / \tau_{b}$ ratio, the "A" device contains plasma $2 t$. or near thasmonuclear temperature during much of its cycle; consequently refueling during the short cycle time may be a problem. The "burned" fuel (alpha particles plus fuel ions) will be able to escape along magnetic field lines during the course of normal end loss, and hence "flushing" the device may be unnecessary. Fuel may be injected either radially or axially. If axial injection is used, Marshall guns [29] are the obvious candidates. The plasma would be "pre-heated" in Marshall guns, possibly eliminating the need for separate shock heating. However, radial injection of "cold" fuel ions ( $\sim 0.1 \mathrm{eV})$, via peripheral gas jets, might be a more attractive alternative.

The daily rate of tritiun consumption can be estimated from

$$
R=m_{T} t_{d} S \quad g / \text { day },
$$

assuming one trition is consumed for each $14-\mathrm{MeV}$ neutron produced, where $\mathrm{m}_{\mathrm{T}}$ is the mass of a triton in grams $\left(5.006 \times 10^{-24} \mathrm{~g}\right), t_{d}$ is the number of seconds per day $(86,400)$, and $S$ is the total neutron soi:ce strength, $1.10 \times 10^{1 /} \mathrm{n} / \mathrm{s}$ from Table II. Sutstituting, we find $R=0.048 \mathrm{~g}$ 'day, or $21.4 \mathrm{~g} / \mathrm{month}$. At present commercial prices of $\$ 0.75 /$ curie $=\$ 7,50 \mathrm{~s} / \mathrm{g}[30,31]$, the montrily tritium fuel bill would be $\sim \$ 11 \mathrm{k}$.

\section{B. Point Design B (Intermittent Trapezoidal Waveform)}

The slow risetime associated with a sinusoidal $B(t)$ waveform can be eliminated if the waveform is made mor - "flat-topped," or trapezoldal, as shown in Fig. 8. An examination of Eq. (43) shows that $\tau_{c} / \tau_{b}$ can become large in the case of continuous, or regular, waveforms (e.g. Fig. 6), only when $\tau / \tau_{b} \gg 1$, which is unacceptable from end-loss considerations. However if the waveform is made intermittent, as shown in Fig. $8, \tau_{c} / \tau_{b}$ can be made essentially arbitrarily large, by increasing the zero-field time between pulses, while keeping $\tau_{b}$, and thereby the machine length, short. The intermittent pulses needn't be trapezoidal, but they can be, since rocating machinery can generate trapezoids easily, and rotating machinery will likely be needed for the intermittent wavetrain. Intermittent pulses are needed in order to tepart significantly from the continuous-sinusoid case. 
Once the constraint on $\tau_{c} / \tau_{b}$ is removed [Eq. (44)], the problem becomes one of maximizing $\langle\mathrm{J}\rangle$ in $\mathrm{Eq}$. (39a), subject to the technology constraint that $\mathrm{B}_{\max }[\mathrm{Eq} .(39 \mathrm{c})]$ not exceed $300 \mathrm{kG}$. Substituting $\mathrm{B}_{\max }=300 \mathrm{kG}$ into $\mathrm{Eq}_{\text {. }}$ (39c) yields $R^{3}\left(\tau_{c} / \tau_{b}\right)=422$. Solving for $\tau_{c} / \tau_{b}$,

$$
\frac{\tau_{c}}{\tau_{i}}=\frac{422}{R^{3}}
$$

and substituting Eq. (51) into Eq. (39a) yields the neutron current in the form

$$
\langle\mathrm{J}\rangle=1.24 \times 10^{13}\left(\frac{2}{1+\lambda}\right)^{17 / 7} \frac{1}{\mathrm{R}^{1 / 7}} \mathrm{n} / \mathrm{cm}^{2} / \mathrm{s} .
$$

The maximum $<J>$ occurs when $R=1$. Thus we arrive at the general theorem that whenever the duty factor $\tau_{c} / \tau_{b}$ is limited by the maximum allowable magnetic field, and not by particle end loss (i.e. the $B(t)$ waveform), then the maximum neutron current is obtained with an applied mirror ratio of unity. The corollary follows that, with no magnetic mirrors, high field operation is implied, since $B_{O}=B_{\max }$ along the entire plasma column when $R=1$.

Due to the $R^{-1 / 7}$ dependerce of $\langle J\rangle$, the penalty in diminished neutron current is small if $R$ should be chosen greater than unity. For example, if $R=2,\langle J\rangle$ is reduced by $\sim 10 \%$ over the $R=1$ case, whereas $\tau_{c} / \tau_{b}$ is reduced by a factor of 8 , from 22 to 53 . With $\mathrm{B}_{\max }=300 \mathrm{kG}$ and $2: 1$ mirrors, $\mathrm{B}_{0}$ is reduced from 300 to $150 \mathrm{kG}$. The plasma length $\mathrm{L}$ is also reduced by a factor of 2. These two factors taken together reduce $\mathrm{EM}_{M}$, the magnetic energy, by a factor of 8 for a given burn time, since $E_{M} \propto \tau_{c}=\left(\tau_{c} / \tau_{b}\right)\left(\tau_{b}\right)$. Thus it seems appropriate, considering the broad picture, to choose an operating point slightly below the "maximum <J>" point, e.g. $R=2$ instead of $R=1$, which will substantially ease the technology demands in this point design. With $\mathrm{R}=2$ we obtain $\langle\mathrm{J}\rangle=1.12 \times 10^{13}[2 /(1+\lambda)] 17 / 7 \mathrm{n} / \mathrm{cm}^{2} / \mathrm{s}$.

It should be noted that the choice of an operating point given above was greatly facilitated by the way in which the LTPF problem is formulated here; the "trade-offs" becane fairly clear.

The arguments given under section V.A. For choosing $\tau_{b}$ (and hence $\tau_{c}$, which is related to $\tau_{b}$ by a constant) as short as possible remain valid. Hence we choose $\tau_{b}=10 \mu \mathrm{s}$ as before. Thus $\tau_{c}=53 \tau_{b}=530 \mu \mathrm{s}(\mathrm{f}=1.89 \mathrm{kHz})$, and $L=1.73 \mathrm{~cm}$. The electron temperature is next found by the iteration procedure given in section $\mathrm{V}-\mathrm{A}$, with the result $\mathrm{T}_{\mathrm{e}}=610 \mathrm{eV}, \lambda=0.122$, and $\mathrm{n}=$ $9.87 \times 10^{16} \mathrm{~cm}^{-3}$.

With a burn time $\tau_{b}$ of $10 \mathrm{ds}$, the risetime can also be $10 \mathrm{Hs}$ [i.e. $\tau_{\mathrm{r}} / \tau_{\mathrm{b}}$

$\simeq 1$ ] without causing excessive end-loss. 8.

Table III lists various design and neutronics parameters for Point Design

Due to the loag pauses between burning pulses in Point Design B, refueling the device with fresh $D-T$ gas can probably be accomplished by conventional gas flow from the ends. A rough estimate of the required filling time can be obtained by calculating $L / 2 c_{s}$, where $L / 2$ is the machine half-length and $c_{s}$ is the sound speed in the filling gas,

$$
c_{s}=\left(\frac{Y k T}{M}\right)^{1 / 2}
$$


in SI units. Here $\gamma$ is the ratio of specific heats $[\gamma=(f+2) / f=7 / 5$ for diatomic molecules, where $f=5$ is the number of degrees of freedom of the molecule], $k$ is Boltzmann's constant $\left(k=1.38 \times 10^{-23}\right.$ joule $\left.{ }^{\circ} \mathrm{K}\right)$, and $M$ is the average molecular mass $\left[M=\left(2 A_{i}\right) m_{H}\right.$, where $A_{1}$ is the atomic weight -5 for an $\epsilon_{i}$ ual mixture of $D-T$ molecules -- and $m_{H}$ is the mass of a hydrogen ion, $1.672 \times 10^{-27} \mathrm{~kg}$. If we assume a filling temperature of $0.1 \mathrm{eV}$ $\left(1140^{\circ} \mathrm{K}\right)$, we find that $\mathrm{c}_{\mathrm{s}}=1624 \mathrm{~m} / \mathrm{s}$, and hence the filling time, $\mathrm{L} / 2 \mathrm{c}_{\mathrm{g}}$, is $533 \mu \mathrm{s}$. This filling time is comparable to the gycle time of $530 \mu \mathrm{s}$. [Note that the r.m.s. speed of a molecule is $(3 \mathrm{kT} / \mathrm{M})^{1 / 2}$ at temperature $\mathrm{T}$; the sound speed calculated above is thus smaller than the r.m.s. speed of the molecules by a factor $(\gamma / 3)^{1 / 2}=0.683$ in the present case, which allows a little leeway].

The average power output of $14-\mathrm{MeV}$ neutrons is the neutron source strength (S) multiplied by the energy per neutron $\left(2.25 \times 10^{-12} \mathrm{~J}\right)$. For $\mathrm{S}=$ $2.73 \times 10^{17} \mathrm{n} / \mathrm{s}$ (Table III), $\mathrm{P}_{\mathrm{n}}=0.617 \mathrm{MW}$.

\section{POWER SUPPLIES}

The power supply for the LTPF is a cruclal item, and the details of its performance and cost will depend heavily on the particular type of power supply used as well as on which LTPF design is chosen.

For an overall circuit $Q$ of 15 and an assumed power consumption $P$ of 300 NW, the power supply must be capable of handiing QF $=4500$ MVA of oscillating power at frequencies of $\sim 33 \mathrm{kHz}$ (Point Design A) or $\sim 1.9 \mathrm{kHz}$ (Point Design $B$ ). The transferred energy in the two cases is $n, 0.13 \mathrm{MJ}$ (design $A$ ) and $\sim$ $2.4 \mathrm{MJ}$ (design B). Either frequency can be obtained with a ringing capacitor bank, but a capacitor bank is presumably not a viable candidate to produce the wideiy-intermittent trapezoidal current pulses required in Point Design $B$. A homopolar device is not able to operate at $33 \mathrm{kHz}$, and probably not at $1.9 \mathrm{kHz}$ [32]. Conventional rotating machinery (i.e. an MG set) could operate at $1.9 \mathrm{kHz}$ without difficulty, and could also produce the desired waveform in Point Design B; however two large machines will be required instead of one, since power taken from the line (at $60 \mathrm{~Hz}$ ) would drive the motor of the MG set, while the generator would drive the theta pinch (at $1.9 \mathrm{kHz}$ ). The cost of the motor and generator has been estimated at $\$ 50 / \mathrm{kW}$ installed [33], or $\$ 100 / \mathrm{kW}$ for the pair. MG sets are not usually employed in circumstances where the power factor of the load is far from zero, as it would be here; consequently problems involving the returning $93.3 \%$ of the electrical power (for a $Q$ of 15) at the end of each pulse can be anticipated. If the MG set has to be costed on the basis of $4500 \mathrm{MVA}$ instead of $300 \mathrm{MW}$, the cost would be prohibitive ( $~ \$ 450 \mathrm{M})$.

The magnitude of the electric current and other circuit parameters for Point Design B are calculated in Appendix III.

For design A the power supply could be either a capacitor bank or a solid-state oscillator, either of which could produce a sinvsoidal current at $33 \mathrm{kHz}$. Since the capacitor bank will, in any case, have to be "pumped" with $300 \mathrm{MW}$ of power to replenish the joule losses each cycle, probably the capacitor bank and oscillator circuit could be used to best advantage together. The capacitor bank and theta-pinch coil can be connected as a resonant RLC tank circuit which will appear as a purely resistive (zero powerfactor) load to the driving oscillator. In this case the oscillator would be rated at $300 \mathrm{MW}$, and for ain estimated cost of $\$ 50 / \mathrm{kW}$ installed [33], would 
$\operatorname{cost} \sim \$ 15 \mathrm{M}$.

The capacitor bank can be costed on the basis of its energy storage, 135 $\mathrm{kJ}$ (Table II). The cost of the high-voltage, low-inductance, 2-MJ Scylla IV-P bank, which utilizes Scyllac-type components, was $\sim \$ 2 \mathrm{M}$ in 1975 [34], or $\sim \$ 1 / \mathrm{J}$ installed. Adding a Factor of 10 for the increased duty factor in the LTPF yields $\$ 10 / \mathrm{J}$ installed, or a total of $\$ 1.35 \mathrm{M}$. The major cost will thus be associated with the solid-state driver.

As an economy measure, a prototype, or proof-of-concept divice, could be built and operated without the solid-state driver. In this case the capacitor bank should ring down in $~ 15$ cycles, for a circuit $Q$ of 15 . This number of cycles should be adequate to test a variety of system components, such as the gas-handling system, and also allow for a comparison of the measured neutron yield vs. theory.

A further discussion of power supplies and circuit parameters is given in Appendix III.

\section{SUMMARY AND CONCLUSIONS}

In previous sections we have examined the possibility of using the linear theta pinch as the basis for a $14-\mathrm{MeV}$ neutron source and Fusion Engineering Research Facility (FERF). The approach has been to express the neutron current and other quantities of interest in the problem (e.g. the machine length, magnetic field energy, ratio of plasma radius to ion gyroradius, etc.) in terms of carefully chosen independent variables which describe the plasma parameters, the theta-pinch coil, and the fower supply which furnishes the coil current. The choice of independent variables used in this study is not unique, but has been found by trial-and-error to permit a systematic optimization of the linear theta-pinch FERF (LTPF) for maximum 14-MeV neutron production, while also realistically incorporating the limitations imposed by the finite (and expensive) power supply. The basic philosophy has been to restrict technological innovations to a minimum, so as to take full advantage of established theta-pinch techniques and experience. Emphasis throughout has been placed on the physics and technology considerations which govern the choice of device parameters. The optimum plasma ion temperature, for instance, is shown to be $5.0 \mathrm{keV}$ for maximum neutron current.

Our studies show that neutron currents of $25 \times 10^{13} \mathrm{n} / \mathrm{cm}^{2} / \mathrm{s}$ can be generated on a test sample located at a radius of $\sim 5.5 \mathrm{~cm}$, between the discharge tube and the compression coil wall (i.e. inside the separate shock-heating coil), in either of two point desiens. The two foint designs are distinguished primarily by their magnetic-field (i.e. coil-current) waveforms, $B(t)$. In Point Design $A, B(t)$ is sinusoidal and continuous, such as might be generated by a resonant LC $\because$ ircuit. In this design the machine length is $67 \mathrm{~cm}$, the magnetic field energy is $135 \mathrm{~kJ}$, and the operating frequency (rep rate) is $33 \mathrm{kHz}$. Strong ( $5: 1$ ) magnetic mirrors are applied at the ends to reduce particle end loss. For a maxirum magnetic field of $300 \mathrm{kG}$ in the mirror regions, the central (umirrored) field strength is $260 \mathrm{kG}$.

In Point Design $B, B(t)$ is trapezoidal and intermittently pulsed, such as might be produced by a motor-generator set. In this design the machine length is $1.7 \mathrm{~m}$, the magnetic field energy is $2.2 \mathrm{MJ}$, and the rep rate is $1.9 \mathrm{kHz}$. The magnetic field in the central (unmirrored) region is $150 \mathrm{kG}$, and 2:1 mirrors are used at the ends.

The question of power supplies for the LTPF is obviously a crucial one, and will require further study. In particular, since the assumed power loss 
in both point designs is $300 \mathrm{NW}$ for an overall circuit $Q$ of 15 , methods for reducing the coil and lead resistance, such as layering or litzing the conductors, should be considered. Since such coils are necessarily complex, they will be subject to new strength and cost considerations. Heat removal, for example, may be more difficult. However if the circuit $Q$ can be increased to 30 , the same LTPF performance and machine parameters will be obtained for a power loss of $150 \mathrm{MW}$, since $Q$ and $P$ appear in the scaling laws only as a product. To put it another way, the LTPF parameters depend on the power transfer in the circuit, and not on the power loss per se. If the power loss can be reduced by increasing the circuit $Q$, the heat removal problem will be correspondingly less severe. The size and cost of the power supply will also be raduced.

A second technology area which will require further study is the matter of refueling the plasma chamber with fresh D-T gas each cycle. Flushing the chamber of spent gas should be easier than refueling, due to the high temperature of the particles ( $\sim 5 \mathrm{keV}$ ) after the burn. Normal particle end loss will suffice to remove much of the burned fuel. The burn-up fraction will be very small for a burn time of $10 \mu \mathrm{s}(\ll 1 \%)$, and therefore most of the tritium will have to be recovered for future use. Injection of new fuel may be either radial or axial. Due to the shorter injection distance, radial fueling may be easier in a high rep rate case, such as Point Design A. If axial injection is used, Marshall guns are obvious candidates in the case of high rep rate. The highly directed velocities (of order $10^{7}-10^{8} \mathrm{~cm} / \mathrm{s}$ ) [29] will be necessary for filling an approximately 1-meter-long device in the available Eew $\mu \mathrm{s}$. In addition, thermalization of the directed plasma energy might eliminate the need for separate shock heating to pre-heat the plasma. In the case of Point Design B, the long interval ( $\sim 0.5 \mathrm{~ms}$ ) between pulses should allow filling the plasma chamber with neutral gas via conventional gasdynamic flow from the ends.

From a plasma physics point of view, no fundamental obstacles to the LTPF concept have been encountered. The projected plasma parameters are familiar, and the confinement times are short $(10 \mu \mathrm{s})$; the corresponding values of the Lawson parameter, $n \tau_{b}$, are $1.6 \times 10^{11}$ and $9.9 \times 10^{11} \mathrm{~s} / \mathrm{cm}^{3}$ for Point Designs A and B, respectively. The principle plasma physics uncertainties relate to the projected high rep rates, and to end-effects problems such as impurities, plasma-wall interactions, etc. Magnetic divertors at the ends might be required to lessen these effects. The presence of magnetic mirrors at the ends introduces regions of unfavorable field curvature which can induce $m=1$ instabilities [2]. This effect is not expected to be impor-



As a very crude estimate, the cost of developing an LTPF based on the principles presented here might be in the range of $\$ 20 \mathrm{M}-\$ 30 \mathrm{M}$. The largest expense is expected to be associated with the development of a suitable power suppiy.

\section{ACKNOWLEDGEMENTS}

This work was performed under the auspices of the U.S. Energy Research and Development Administration. 


\section{APPENDIX I - NEUTRONICS TERMINOLOGY}

The neutron-transport terminology used in the FERF or reactor field can be confusing to the casual reader because of sometimes inconsisient or conflicting usage. For this reason we begin by defining some of the terms appearing in this report (based in part on ref [26]).

1. Neutron Current Density. The neutron current density, often abbreviated to current when the implication is obvious, is the net number of neutrons crossing a unit area, oriented in some given direction, in unit time. The current may be thought of as the net sum of all neutrons crossing a small test djsk from both sides in any direction. Since the disk has a vector unit normal, the current as defined here is a vector, even though it includes neutrons with random directions. The current is expressed as ne'itrons per $\mathrm{cm}^{2}$ per $\mathrm{sec}$, or $\mathrm{n} / \mathrm{cm}^{2} / \mathrm{s}$, and in this report has the symbol $\mathrm{J}$.

2. Neutron Flux Density. The neutron flux density, often abbreviated to flux when the implication is obvious, is the product of neutron density and velocity. The flux is a scalar, and although usually expressed as neutrons per $\mathrm{cm}^{2}$ per $\mathrm{sec}\left(\mathrm{n} / \mathrm{cm}^{2} / \mathrm{s}\right)$, might be less confusing if expressed as $\left(\mathrm{n} / \mathrm{cm}^{3}\right) \mathrm{x}$ $(\mathrm{cm} / \mathrm{s})$. The flux may be thought of as the sum of all neutrons entering from any direction a small test sphere having unit projected area. In this report its symbol is $\phi$.

3. Neutron Fluence Density. The neutron fluence density, often abbreviated to fluence when the implication is obvious, is the time integral of the flux. The fluence density is a scaler with units of $\mathrm{n} / \mathrm{cm}^{2}$. The total fluence is the integral of the fluence density, or simply the total neutrons. In this report fluence density has the symbol $\mathrm{F}$.

4. Uncollided Neutrons. The term "uncollided" refers to primary neutrons, as differentiated from back-scattered neutrons. Uncollided (or source or primary) neutrons approach the first wall from the plasma side only, and in the case of a D-T burning FERF have an energy of $14.06 \mathrm{MeV} \pm$ a plasma ion thermal energy component.

The average neutron energy is increased somewhat because of the kinetic energy associated with the relative motion of the reacting ions, and this effect has been taken into account in arriving at $14.06 \mathrm{MeV}$ for the center-ofmass neutron energy for the $D-T$ reaction. In addition to this effect, which slightly shifts the location of the peak, a broadening of the neutron spectrum will cccur due to the distribution of relative ion velocities. The full width at half maximum ( $f w h m$ ) is related to the ion kinetic temperature by the equation [35]

$$
\text { fwhm }(\mathrm{MeV})=0.177 \sqrt{\mathrm{kT}(\mathrm{kev})}
$$

The width of this distribution is much larger than $\mathrm{kT}$ for most cases of interest. For example, if $\mathrm{kT}=5 \mathrm{keV}$, the width of the $14-\mathrm{MeV}$ neutron peak 
is $0.40 \mathrm{MeV}$, or a factor of eighty greater than $\mathrm{kT}$. (Note that an INS of the wind-tunnel type does not produce this type of spectrum).

5. Total Source Strength. As used in this report, the total source strength, $S$, for neutrons refers to the integral of uncollided neutron current over any surface enclosing the source. Source strength is expressed in units of neutrons per $\sec (n / s)$, and may be thought of as the rate of $14-\mathrm{MeV}$ neutron production for the entire plasma column.

6. "Average" vs. "Instantaneous" Values. In a pulsed neutron source such as the LTPE, the neutrons are produced intermittently. From the end of one burn phase until the start of the next, the neutron fluence remains constant. The neutron current and flux may be described either by their instantaneous values, which are assumed constant during the burn, or by their average values, which are time-averages over a complete cycle (i.e. the time between successive burning pulses). In this report time-averaged quantities are denoted by angle brackets, i.e. $\langle\mathrm{J}\rangle$.

7. Neutron Current vs. Neutron Flux. Using the above definitions, it follows that the uncollided neutron current on the first wall of an LTPF is numerically equal to the uncollided flux only in the special case of purely radial neutron velocity. In any actual device the productior of neutrons with purely radial velocity will not occur; there will always be an axial neutron component. The closest approach to a purely radial velocity would be if the plasma were an infinite line source, in which ase the ratio of uncollided current to uncollided flux $(\mathrm{J} / \phi)$ can be shown to be [36] $2 / \pi=$ 0.64 (i.e. the average value of $\cos \theta$ as $\theta$ goes from 0 to $\pi / 2$ ). If the neutron velocity were purely isotropic (as would be caused, for example, if the plasma existed as a thin annulus, or sheath, adjacent to the wall), the ratio $(\mathrm{J} / \phi)$ would be [36] $1 / 2$. In an actual theta pinch, the uncollided current and uncollided flux are related by a factor lying somewhere betweei 0.5 and 0.64 ; for present purposes we will assume $\mathrm{J} / \phi=0.5$.

8. "Total" Flux vs. "Uncollided" Flux. The total neutron flux $\left(\phi_{T}\right)$ contains a contribution from back-scattered neutrons having energies less than $14 \mathrm{MeV}$. A proper calculation of the total flux requires complex computer programs which take into account non-radial neutron velocities, scattering cross sections for the various wall materials, multiple energy groups for the neutrons, etc. Bulk material damage effects are probably more closely related to the total neutron flux at a point than to the uncollided flux. Neutronics calculations for the RTPR blanket [6] indicate that the total neutron flux is abont 10 times the uncollided flux in a fusion reactor. We will assume the same ratio here.

In this report we will be concerned primarily with calculating the unccllided neutron current. 
A. Derivation of Staged-Heating Equations

Staged heating in theta pinches has been discussed in detail elsewhere [13-15]. Those treatments have usually assumed equal temperatures for the electrons and ions after the "equilibration" phase (prior to the start of adiabatic compression). The staged-heating equation [Eq. (7)] is derived below in SI (MKS) units for the case of unequal electron and ion temperatures.

We begin by assuming that at $t=0$ the implosion of a cylinder of gas is initiated by applying $E_{\theta}$ to the boundary of radius $b$. The initial gas atom

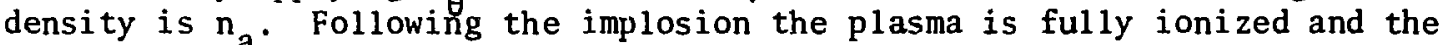
electrons and ions settle down to a state characterized by $n_{s}, B_{s}, a_{s}, T_{e s}$, and $\mathrm{T}_{\mathrm{is}}$. The piasma is then further compressed to a final state $\mathrm{n}, \mathrm{B}, \mathrm{a}, \mathrm{T}_{\mathrm{e}}$, and $\mathrm{T}_{\mathrm{i}}^{\mathrm{is}}$. We will use the so-called "free-expansion" model of shock heating [15], in which the gas is shocked by a two-stage process. An initial piston field of magnitude $B_{s} / \sqrt{2}$ is suddenly removed at time $t$, when the sheath has advanced to position $a / b=1 / 3$. A larger field, $B_{s}$, is then reapplied at $3 / 2 t$, when all ions have advanced to the opposite wall, reflecting them with velocity $2 \mathrm{v}$. When pressure equilibrium is achieved, the radius a is, related to the starting radius by the dimensionless ratio $x_{s}$; that is,

$$
a_{s}=x_{s} b .
$$

The value of $x_{\text {fepends }}$ upon complicated particle dynamics which take place during the implosion. Numerical simulations [15] give $x_{s}=0.76$ for the freeexpansion case, whereas simple kinetic calculations $[15]^{\text {S }}$ give $x_{5}=0.76$. We will eventually use $x_{s}=0.76$, but for the present $x_{s}$ is retained as a free parameter.

The plasma ion density after the implosion event is

$$
n_{s}=\frac{n_{a}}{x_{s}^{2}}
$$

(for particle conservation). The magnetic field and electric field are related by $\bar{E}=\bar{V} \times \bar{B}$; since $B=B_{s} / \sqrt{2}$ during the acceleration of the ions,

$$
E_{\theta}=\left(\frac{B_{s}}{\sqrt{2}}\right) U_{s}
$$


The "effective" piston velocity in Eq. (II-3) is $U_{s} / \sqrt{2}$. During the first reflection the ion velocity is doubled to $\sqrt{2} u_{\text {. }}$. During the second reflection the ion velocity is doubled once more, to $2 \sqrt{2} \mathrm{~d}$. The momentum-balance equation, $p=1 / 2 \mathrm{mv}^{2}$, takes the form

$$
\frac{B_{s}^{2}}{2 \mu_{0}}=4 m_{i} n_{a} u_{s}^{2}
$$

Eliminating $U_{s}$ between Eq. (II-3) and Eq. (II-4) yields

$$
E_{\theta}=\frac{B_{s}^{2}}{4\left(\mu_{0} m_{i} n_{a}\right)^{1 / 2}} \text {. }
$$

If the plasma is adiabatically compressed from state "s", the temperature is related to the plasma volume by [ref. (10), p 124]



where $f=$ number of degrees of freedom for the particles. For $f=3$,

$$
\frac{T}{T_{s}}=\left(\frac{a_{s}}{a}\right)^{4 / 3} .
$$

The relationship between the plasma temperature and confining magnetic field in an adiabatic compression is [ref (10), p 126]:

$$
\frac{T}{T_{S}}=\left(\frac{B}{B_{S}}\right)^{2(\gamma-1) / \gamma}
$$

where $\gamma=(f+2) / f$ is the ratio of specific heats. Equation (II-8) is only valid in the case $\beta=1$, i.e. no trapped internal field. For $f=3$,

$$
\frac{T}{T_{s}}=\left(\frac{B}{B_{s}}\right)^{4 / 5} .
$$

Eliminating $T / T_{s}$ between Eq. (II-7) and Eq. (II-9) yields 


$$
\frac{a}{a_{s}}=\left(\frac{B}{B_{s}}\right)^{-3 / 5} \text {. }
$$

Conservation of particles requires

$$
n_{s} a_{s}^{2}=n a^{2}
$$

Equations $(I I-10)$ and $(I I-11)$ yield

$$
\frac{n}{n_{s}}=\left(\frac{B}{B_{s}}\right)^{6 / 5} .
$$

Collecting results, the adiabatic laws for $a=1, f=3$ compression are

$$
\left.\begin{array}{l}
\frac{T}{T_{s}}=\left(\frac{B}{B_{s}}\right)^{4 / 5} \\
\frac{a}{a_{s}}=\left(\frac{B}{B_{s}}\right)^{-3 / 5} \\
\frac{n}{n_{s}}=\left(\frac{B}{B_{s}}\right)^{6 / 5}
\end{array}\right\} \text {. }
$$

Dividing a and $a_{s}$ in Eq. (II-13) by b yields

$$
B_{s}=\left(\frac{x}{x_{s}}\right)^{5 / 3} B
$$

where $x=a / b$. Particle conservation requires

$$
n_{a}=x^{2} n
$$

and pressure balance at $\beta=1$ yields 


$$
n=\frac{B^{2}}{2 \mu_{0}(1+\lambda) k T}
$$

$\left(\lambda=\mathrm{T}_{\mathrm{e}} / \mathrm{T}_{\mathrm{T}}=\mathrm{T} / \mathrm{T}\right)$. Substituting $\mathrm{n}$ from $\mathrm{Eq} .(\mathrm{II}-16), \mathrm{n}_{\mathrm{a}}$ from $(\mathrm{A}-15)$, and $B_{s}$ from (lI-14) into Eq. (II-5) yields for $E_{\theta}$

$$
E_{\theta}=\left(\frac{1+\lambda}{8 m_{i}}\right)^{1 / 2}\left(\frac{a}{b}\right)^{7 / 3}\left(\frac{1}{x_{s}}\right)^{10 / 3} B_{0}(k T)^{1 / 2},
$$

which is the desired result.

Assuming $x_{s}=0.76$ and $m_{i}=\left(m_{p}+m_{T}\right) / 2=4.1756 \times 10^{-27} \mathrm{~kg}$, and setting $B=B_{0}$ and $b={ }^{3} b_{1}$ yields in our notation

$$
E_{\theta}=0.244\left(\frac{1+\lambda}{2}\right)^{1 / 2}\left(\frac{a}{b_{1}}\right)^{7 / 3} \quad B_{0} T^{1 / 2}
$$

( $E_{\theta}$ in $\mathrm{kV} / \mathrm{cm}$ for $\mathrm{B}_{\mathrm{o}}$ in $\mathrm{kG}$ and $\mathrm{T}$ in $\mathrm{keV}$ ). In the case of equal electron and ion temperature, $\lambda^{\circ}=1$ and Eq. (II-18) reverts to the form given in ref [37].

B. Radial Dependence of $E_{\theta}$.

The radial dependence of $E_{\theta}$ is obtained by integrating Ampere's law, $\nabla \times \bar{E}=-\partial \bar{B} / \partial t$, over the open cross-sectional area of the coil:

$$
\int_{\operatorname{coil} 1} \nabla \times \bar{r} \cdot d \bar{A}=-\int_{\operatorname{coil}}^{\operatorname{area}} \frac{\partial \bar{B}}{\partial t} \cdot d \bar{A} .
$$

Stokes' law is used to transform the left side of Eq. (II-19) into a line integral,

$$
\int \bar{E} \cdot d \bar{l}=-\int_{\substack{\text { coil } \\ \text { area }}} \frac{\partial \bar{B}}{\partial t} \cdot d \bar{A}
$$

The line integral is taken around a circular path of radius $\mathbf{r}$ centered on the tube axis: 


$$
\int_{0}^{2 \pi} E_{\theta}(r d \theta)=-\int_{0}^{r} \frac{\partial B}{\partial t}(2 \pi r d r)
$$

If we assume $B_{z}$ is spatially uniform within $r$, then $E_{\theta}$ is constant on the boundary, by symmetry, and the integration is trivial?

$$
E_{\theta}(2 \pi r)=-\frac{\partial B_{2}}{\partial t}\left(\pi r^{2}\right)
$$

thus

$$
\mathrm{F}_{\theta}=-\frac{\mathrm{r}}{2} \quad \frac{\partial \mathrm{B}}{\partial \mathrm{t}}
$$

in SI units.

If $B(t)=B$ sin $\omega t \quad($ ff Section $v)$, then $\frac{\partial B}{\partial t}=\omega B$ cos $w t$ and $E_{\theta}$ has its
imum value at $t=0$. In our usual units the maximum value of $E_{\theta}$ ss

$$
\mathrm{E}_{\theta}=-\frac{10^{-8}}{2} \mathrm{r} w \mathrm{~B}_{0}
$$

$\left(\mathrm{E}_{\theta}\right.$ in $\mathrm{kV} / \mathrm{cm}$ for $\mathrm{r}$ in $\mathrm{cm}$, w in $\mathrm{s}^{-1}$, and $\mathrm{B}_{\mathrm{o}}$ in $\left.\mathrm{kG}\right)$.

If $B(t)=B_{0}\left(t / \tau_{r}\right)$ (i.e. a trapezoidal waveform), then in our units,

$$
E_{\theta}=-\frac{10^{-8}}{2} \quad r \frac{B_{0}}{\tau_{T}}
$$




\section{A. Parameters for Point Designs A and B}

Coil Current. Neglecting magnetic mirrors, the maximum coil current. $I$ is related to the maximum magnetic field $B_{0}$ by the solenoid formula, $B_{0}=$ $+\pi N I / 10 \mathrm{~L}$, where $\mathrm{L}$ is the coil length in $\mathrm{cm}, \mathrm{N}$ is the number of coil turns, and $B_{0}$ is in gauss for $I$ in amperes. Thus

$$
\begin{aligned}
I & =\frac{10 \mathrm{~B}_{0} \mathrm{~L}}{4 \pi \mathrm{N}} \\
& =\left\{\begin{array}{lll}
\frac{3.05}{\mathrm{~N}} & \mathrm{MA} & \text { (design } \mathrm{A}) \\
\frac{20.7}{\mathrm{~N}} & \mathrm{MA} & \text { (design } \mathrm{B})
\end{array}\right.
\end{aligned}
$$

using values from Tables II and III.

Coil Inductance. The inductance of an $\mathrm{N}$ turn solenoid of length $\mathrm{L}$ and radius $b_{2}$ is $(\mathcal{L}$ in $\mathrm{nH}$ for dimensions in $\mathrm{cm}$ ) [38]

$$
\begin{aligned}
\mathcal{L}_{\text {coil }} & =\frac{4 \pi^{2} \mathrm{~N}^{2} \mathrm{~b}_{2}^{2} \mathrm{~L}}{\mathrm{~L}^{2}+4 \mathrm{~b}_{2}^{2}} \\
& =\left\{\begin{array}{lll}
27.9 \mathrm{~N}^{2} & \mathrm{nH} & \text { (A) } \\
11.1 \mathrm{~N}^{2} & \mathrm{nH} & \text { (B) . }
\end{array}\right.
\end{aligned}
$$

Coil Resistance. The electrical resistance $R$ of a multi-turn solenoid having total conductor length $l$ and conductor cross-sectional area $A$ can be found from $R=\eta l / A$, where $\eta$ is the conductor electrical resistivity. For an $N$-turn solenoid of length $L$, average conductor radius $\vec{b}$, and skin depth $\delta$, we find $\ell \sim 2 \pi \mathrm{Nb}, A \sim L \delta / N$, and thus

$$
\mathrm{R} \simeq \frac{2 \pi \bar{b} \eta \mathrm{N}^{2}}{\mathrm{~L} \delta}
$$

( $R$ in ohms for dinensions in $\mathrm{cm}$ and resistivity in ohm-cm). The skin depth $\delta$ of a conductor is given by (SI units) 


$$
\delta=\sqrt{\frac{2 n}{\mu_{0} \omega}}
$$

For the resistivity we take $\eta=4 \times 10^{-6} \Omega-\mathrm{cm} \quad$ [39], the value for commercial Amzirc (copper-zirc) alluy at a temperature of $300^{\circ} \mathrm{C}$. For design $\&$ ( $f=33 \mathrm{kHz}), \omega=2.1 \times 10^{5} \mathrm{~s}^{-1}$ and $\delta=0.6 \mathrm{~mm}$; for design $B\left(f=1.9 \mathrm{kH}_{\mathrm{z}}\right), w=1.2 \times 10^{4} \mathrm{~s}^{-1}$ and $\delta=2.3 \mathrm{~mm}$. For $\mathrm{b} \sim \mathrm{b}_{2}=7 \mathrm{~cm}$ the coil resistance is

$$
R=\left\{\begin{array}{llll}
4.4 \times 10^{-5} N^{2} & \Omega & \text { (A) } \\
4.4 \times 10^{-6} N^{2} & \Omega & \text { (B). }
\end{array}\right.
$$

Joule Losses. Neglecting eddy currents, the joule losses in the compression coil are due to the transport current I:

$$
\begin{aligned}
E_{J} & =\int_{0}^{T_{c} I^{2}(t) R d t} \\
& =\left\{\begin{array}{c}
\frac{3}{2} I^{2} R \tau_{b}=6.14 \mathrm{~kJ} \\
5 / 3 I^{2} R \tau_{b}=31.4 \mathrm{~kJ}
\end{array}\right.
\end{aligned}
$$

by direct integration of the design $A$ and design $B$ waveforms (see Tables II and III). Note that the joule losses are independent of the numbers of turns in the coil.

Circuit Q. The quality factor $Q$ for the coil, defined as (energy transferred to the cril per cycle)/(energy lost in the coil per cycle), forms an upper bound for the circuit $Q$, which is necessariiy sma:ler.

Using Eq. (III-6) and Tables II and III, we find

$$
Q_{\text {coil }}= \begin{cases}135 \mathrm{~kJ} / 6.14 \mathrm{~kJ}=22 & \text { (A) } \\ 2.39 \mathrm{MJ} / 31.4 \mathrm{~kJ}=76 & \text { (B) } .\end{cases}
$$

These values for the coil- $Q$ are compatible with our assumption that the circuit-Q for LTPF is $\sim 15$. 
If the waveform shown in Fig. 6b had been chosen for point design A instead of the waveform in Fig. 6a, the joule losses in Eq. (III-6) would have been $9 / 8 \mathrm{I}^{2} \mathrm{R} \tau_{\mathrm{b}}=4.6 ! \mathrm{kJ}$ and the coil $Q$ would have been 29 instead of 22. Finally, if the DC bias field of Fig. 6b were generated by a lossless superconducting coil, the joule losses in Eq. (III-6) would have been $3 / 8 \mathrm{I}^{2} \mathrm{RT}_{\mathrm{T}}=1.54 \mathrm{~kJ}$ and the coil $\mathrm{Q}$ would have been 88 instead of 22 . In this latter case, however, refrigeration losses should also be included to make a valid comparison.

\section{B. Capacitor Bank Characteristics (Point Design i).}

Energy Transfer Efficiency. If we define the transfer efficiency a as the fraction of the bank energy (or voltage) teansferred to the load. a can be written as

$$
\alpha=\frac{\mathcal{L}_{\text {coil }}}{\mathcal{L}_{\text {coil }}+\mathcal{L}_{\text {source }}}
$$

where $\mathcal{L}_{\text {sofure }}$ refers to all the circuit inductance not in the load coil. For example, In the Scyllac $8-\mathrm{m}$ toroidal sector experiment [21] $L_{\text {coil }}$ was $\sim 3 \mathrm{nH}$ ard $\mathcal{L}$ was $\eta 0.5 \mathrm{nH}$, giving $\alpha=0.86$ [4G]. If we assume ${ }^{2}$. transfer efficurency of, say, $80 \%$ for the LTPF, then Eq. (III-8) requires

$$
\begin{aligned}
\mathcal{L}_{\text {source }} & =\frac{1-\alpha}{\alpha} \mathcal{L}_{\text {coi } 1} \\
& =6.98 \mathrm{~N}^{2} \mathrm{nH} \quad \text { (A). }
\end{aligned}
$$

If the design-A coil were $1 \mathrm{~m}$ long instead of $66.5 \mathrm{~cm}, \mathcal{L}$ coil would be reduced to $\sim 18.6 \mathrm{~N}^{2} \mathrm{nH}$ and $\mathcal{L}$ in Eq. (III-9) to $\sim 4.64 \mathrm{~N}^{2}$ n⿴囗. The equivalent $1-\mathrm{m}$ values for the Scyllac $8-\mathrm{m}$ sector experiment (actual length $=8.4 \mathrm{~m}$ ) are $\leftarrow_{\text {source }}=4.2 \mathrm{nH} / \mathrm{m}$ and $\mathcal{L}_{\text {coil }}=25 \mathrm{nH} / \mathrm{m}$.

We conclude that the LTPF does not require a bank of lower inductance than Scyllac, even for the 'worst' case of $N=1$. A single-turn coil will certainly be the simplest to fabricate, from the viewpoints of both mechanical strength and cost. Therefore the logical choice, at least for prototype development, is $N=1$. For a single-turn coil the relevant circuit values become: $I=3.05 \mathrm{MA}, R=0.44 \mu \Omega, \mathcal{L}_{\text {coi } 1}=27.9 \mathrm{nH}$, and $\mathcal{L}_{\text {source }}=6.98 \mathrm{nH}$ (for $80 \%$ transfer efficiency).

Bank Energy. With a transfer efficiency of $\alpha=80 \%$, the bank energy is greater than the coil energy by $25 \%$ :

$$
E_{\text {bank }}=\frac{E_{m}}{\alpha}
$$


Banl. Capacity. The bank capacity is choser to give the correct resonant frequency for the total circuit:

$$
\begin{aligned}
C & =\frac{1}{\omega^{2} d_{T}^{2}} \\
& =650 \mu \mathrm{F}
\end{aligned}
$$

where $\mathcal{L}_{\mathrm{T}}=\mathcal{L}_{\text {coil }}+\mathcal{L}_{\text {source }}=34.9 \mathrm{nH}$ and $\omega=2.1 \times 10^{5} \mathrm{~s}^{-1}$ for design $\mathrm{A}$. Bank Voltage. The bank voltage is chosen to give the desired bank energyr. Thus

$$
\begin{aligned}
V & =\left(\frac{2 E_{\text {bank }}}{C}\right)^{1 / 2} \\
& =22.8 \mathrm{kV} \quad \text { (A). }
\end{aligned}
$$

Shock-Heating Requirements. The shock-heating electric field $E_{\theta}$ has been specified as $1.0 \mathrm{kV} / \mathrm{cm}$, at a radius $b_{1}=5.0 \mathrm{~cm}$. The corresponding applied voltage at the $6.5 \mathrm{~cm}$ radius of the shock coil is $53 \mathrm{kV}$ (see Sec. IV-C). Since the compression bank alone supplies over $40 \%$ of this voltage at time

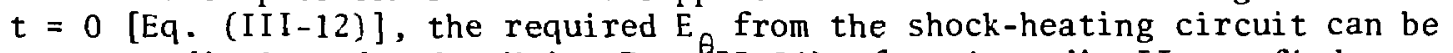
correspondingly reduced. Using Eq. (II-24), from Appendix II, we find

$$
\begin{aligned}
E_{\theta} & =\frac{-10^{-8}}{2} r w B_{0} \\
& =0.30 \mathrm{kV} / \mathrm{cm}
\end{aligned}
$$

at $r=5 \mathrm{~cm}$, due to the compression bank alone. Therefore the shock-heating coil need supply only $1 \mathrm{kV} / \mathrm{cm}-0.3 \mathrm{kV} / \mathrm{cm}=0.7 \mathrm{kV} / \mathrm{cm}$ - a very $\mathrm{mild}$ requirement.

C. Rotaiing Machinery Characteristics (Point Design B).

Maximum rotor speed. The maximum tip speed of the spinning rotor will be limited by strength-of-materials considerations (centrifugal force) to around 200-400 m/s [41]. An additional factor of two can be gained in the relative speed between rotor and stator if rotor and stator are both counter-rotated at the maximum tip speed [41]. However this feat is technologically difficult 
to accomplish, particularly with large machines. If we assume, conservattively, that $300 \mathrm{~m} / \mathrm{s}$ is the maximum tip speed, a current pulse $30 \mu$ wide would require a pole-piece width of $\sim 1 \mathrm{~cm}$. Such widths imply rather narrow air gaps, and consequently expensive construction. The technology is probably within the state of the art. Rotating machinery has traditionally been reliable in steady-state service. A $1-\mathrm{MW}, 10 \mathrm{kHz}$ inductor-alternator generator has been successfully operated by Westinghouse (cost $\sim \$ 50 / \mathrm{kW}$ ) [33].

Output Voltage. The output voltage required from the generator is approximitely

$$
V=\mathscr{L}_{T} \quad \frac{\mathrm{d} I}{\mathrm{dt}}
$$

Assuming $I(t)=I\left(t / \tau_{r}\right), 0<t<\tau_{r}$ (i.e. for a trapezoid) then $\mathrm{dI} / \mathrm{dt}=\mathrm{I} / \tau_{\mathrm{r}}$. For $I=20.7 \mathrm{MA}, \tau_{\mathrm{r}}=r_{10 \mathrm{Hs}}$, and $\mathcal{L}_{\mathrm{T}}=14 \mathrm{nH}$ (11 $\mathrm{nH}$ for the coil inductance and a cransfer efficienty of $80 \%$ ), we find $V=30 \mathrm{kV}$ (B).

Shock-Heating Requirements. For a linearly rising magnetic field, the contribution to $E_{\theta}$ from the compression field alone is given by Eq. (II-25), Appendix II:

$$
\begin{aligned}
E_{\theta} & =\frac{-10^{-8}}{2} r \frac{\mathrm{B}_{\mathrm{o}}}{\tau_{\mathrm{r}}} \\
& =0.38 \mathrm{kV} / \mathrm{cm}
\end{aligned}
$$

assuming $\mathrm{r}=5 \mathrm{~cm}, \mathrm{~B}_{0}=150 \mathrm{kG}$, and $\tau=10 \mu \mathrm{s}$. The shock-heating coil therefore has to supply $(1.0 \mathrm{kV} / \mathrm{cm}-6.38 \mathrm{kV} ! \mathrm{cm})=0.62 \mathrm{kV} / \mathrm{cm}$ (a total of $33 \mathrm{kV}$ ) at a radius of $6.5 \mathrm{~cm}$ in design $\mathrm{B}$ - a value comparable to present-day theta pinches without separate shock coils. Thus the shocl-heating requirements are mild.

Power-Factor Considerations. The largely inductive load means that a large fraction of the power transferred per cycle (4500 MVA in this design) will be returned to the power supply. When the power supply is a generator, the loadcurrent buildup occurs at the expense of shaft power, most of which is returned during the current-decay phase. In order to keep large reactive-power oscillations from the electrical grid, an energy storage system such as a mechanical flywheel may be used [42]. In order to have synchronous operation, the stored energy in the flywheel should greatly exceed the energy transferred per cycle to the compression coil. In Point Design B, speed constancy of the generator to within $\sim 1 \%$ requires a flywheel energy storage of $\sim 100 \mathrm{E}_{M}=$ $24 \dot{\mathrm{u}} \mathrm{MJ}$, which is not difficult. With this scheme the electrical power delivered to the motor-generator-flywheel set need not exceed $300 \mathrm{MW}$. 


\section{REFERENCES}

1. Fusion Power Schedule Chart, published by USAEC-DCTR, Wash. D.C., (Oct. 1972).

2. K. S. THOMAS, H. W. HARRIS, F. C. JAHODA, G. A. SAWYER, and R. E. SIEMON, "Plasma Experiments on the Linear Scyliuc Theta Pinch," Phys. Fluids 17, 1314 (1974).

3. T. A. OLIPHANT, Los Alamos Scientific Laboratcry, Private Communication (1974).

4. R. F. POST and F. L. R ${ }^{r} B E$, "Fision Reactors as Future Energy Sources," Science 186, 397 (1974).

5. F. L. RIBE, "Fusion Reactor Systems," Rev. Mad. Phys. 47, 7 (1975).

6. R. A. KRAKOWSKI, F. L. RIBE, T. A. COULTAS, and A. J. HATCH, "An Engineering Design Study of a Reference Theta-Pinch Reactor (RTPR), "USAEC Rep. LA-5336/ANL-8019, Vo1. I (1974).

7. T. A. COUlTAS, J. E. DRALEY, V. A. MARONI, and R. A. KRAKOWSKI, "An Engineering Design of a Reference Theta-Pinch Reactor (RTFR) - An Environmental Impact Study," USERDA Rep. LA-5336/ANL-8019, Vol. II (1975).

8. W. G. PRICE, "Blarket Neutronic Studies for a Fusion Power Reactor," Proc. Fifth Sympusium on Engineering Problems of Fusion Research, Princeton, N.J., IEEE Pui. 73CH0843-3-NPS (1973), p 75.

9. G. A. EMMERT, R. W. CONN, and G. L. KJLCINSKI, "The Wiscons in Tskamak Reactor Design - A: Overview," Proc. Fifth Symposium on Engineering Problems of Fusion Research, Princeton, N.J., IEEE Pub. 73CH0843-3-NPS (1973), p 112.

10. S. GLASSTONE and R. H. IOVBERG, Controlled Thermoruclear Reacticis, Van Nostránd, New York (i̧̧SO), Chapter 2.

11. W. R. ELLIS, "Fusion Reactor Applicatiors of the تigh-Density Linear Theta Pinch," Proc. First Topical vieetirs on thie Techrology of Controlled Nuclear Fusion, San Diego, CA, USAEC CONF-740402-PI, 1, (1974), p i75.

12. W. R. ELLIS, "CTR Afplications of the High Jensity Linear Theta Pinch," Nucl. Fusion 15, 2 (1975).

33. F. L. RiBE, ed., "Proposed Experiments or. 立azing, Staging, ani Stabilization of Theta Pinches," USAEC Rep. LA-5CZE-P (Kevisec̈), zos Aianos Scieniific Laboratory (1973).

14. F. L. RIBE, "Parametric Study of a Long, Senarazed-Shock $5-3: 2$

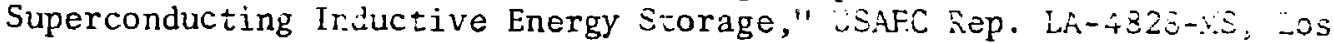
Alamos Scientific Laboratory (1971). 
15. J. P. FREIDBERG, R. L. MORSE, and F. L. RIBE, "Staged Theta Pinches with Implosion Heating," Proc. Texas Symposium on the Technology of Controlled Thermonuclear Fusion Experiments and the Engineering Aspects of Fusion Reactors, USAEC Rep. CONF-721111 (1972), p 812.

16. J. P. FREIDBERG and H. WEITZNER, "Endloss from a Linear Theta Pinch," Nuc. Fusion 15, 2 (1975).

17. J. P. FREIDBERG, Los Alamos Scientific Laboratory, Private Communication (1974).

13. W. R. ELLIS and G. A. SAWYER, "Scaling Laws for the Linear Theta Pinch, I: A Comparison of Magnetic and Laser Heating," USAEC Rep. LA-5434-MS, Los Alamos Scientific Laboratory (1973).

19. R. F. McKENNA, R. KRISTAL, and K. S. THOMAS, "Measurements of Plasma Density Distribution and Current-SheathStructure in the Implosion Phase of a Theta-Pinch Discharge," Phys. Rev. Lett. 32, 409 (Feb. 1974).

20. E. M. LITTLE, W. E. QUINN, and G. A. SAWYER, "Plasma End Losses and Heating in the 'Low-Pressure' Regime of a Theta Pinch," Phys. Fluids $\underline{8}, 1168$ (1965).

21. W. R. Ellis, F. C. JAHODA, R. KRISTAL, W. E. QUINN, F. L. RIBE, G. A. SAWYER, and R. E. SIEMON, "Plasma Equilibrium and Stability in the Scyllac Toroidal Sector Experiments," Nuc. Fusion 14, 841 (1974).

22. M. KEILHACKER, M. KORNHERR, F. LINDENBERGER, G. MARET, H. NIEDERMEYER and K. H. STEUER, Proc. Second Topical Cont. on Pulsed High-Beta Plasmas, Garching, Germany, Max-Planck-Inst.-für-Plasmaphysik Rep. IPP 1/127 (1972), paper D3.

23. J. MARSHALI, USAEC Report LA-5656-PR, Los Alamos Scientific Laburatory $(1974), \mathrm{p} 57$.

24. T. BUTT, UKAEA Culham Laboratory, Abingdon, Oxon, England, Private Communication (1969).

25. V. V. ABAJIAN and A. M. FISHMAN, "Supn?ying Enriched Uraniun," Physics Today 26, 23 (Aug. 1973).

26. C. R. EMIGH, J. E. BROLLEY, and M. C. CLINE, "A Proposal for a 14-MeV Inten:- Neutron Source at Los Alamcs, New Mexico," USAEC Rep. LA-5191-P, Los Alamos Scientific Laboratory (1973).

27. K. W. HANKS, G. P. BOICOURT, and A. G. BAILEY, "250-kG Mirror Coil Development for the Linear Scyllac Experiment," Proc. Fifth Sym. on Engineering Problems of Fusion Research, Princeton, N.J., IEEE Pub. 73CH0843-3NPS (1973), p 314.

28. R. L. MORSE, "Electron Temperatures and Thermal Conduction in High-Energy Theta Pinches," Phys. Fluids 16. 545 (1973). 
29. J. MARSHALL and T. F. STRATTON, "Collision of Two Plasmas," Nucl. Fusion: 1962 Supp1. Part 2, 663 (2962).

30. D. B. HENDERSON, "LASL Intense 14-MeV Neutron Source," USAEC Rep. LA4863-MS, Los Alamos Scientific Laboratory (1972).

31. Federal Register, Vo1. 33, No. 190 (Sept. 28, 1968).

32. J. MARSHALL, Los Alamos Scientific Laboratory, Private Communication (1974).

33. L. A. KILGORE, Westinghouse Corporation, Director of Engineering (retired), E. Pittsburgh Division, Private Communication (1975).

34. W. R. ELLIS, W. B. RIESENFELD, and G. A. SAWYER, "Proposal for the Construction of a Scylla IV-P Confinement Studies Theta Pinch," USAEC Rep. LA-5474-P, Los Alamos Scientific Laboratory (1973).

35. D. W. MUIR, "Sensitivity of Fusion Reactor Average Cross Sections to Thermal Broadening of the 14-MeV Neutron Peak," USAEC Rep. LA-5411-MS, Los Alamos Seientific Laboratory (1973).

36. D. W. MUIR, Los Alamos Scientific Laboratory Private Communication (1974).

37. S. C. BURNETT, W. R. ElLIS, T. A. OIIPHANT, and F. L. RIBE, "A Reference Theta-Pinch Reactor (RTPR): A Study of a High-Beta Fusion Reactor Rased on the Theta Pinch," USAEC Rep. LA-5121-MS, Los Alamos Scientific Laboratory (1972).

38. R. S. DIKE, E. L. KEMP, and W. E. QUINN, "Proposed Straight Theta-Pinch Devices Energized by the Energy Storage Supply of the Toroidal ThetaPinch (Scyllac)," USAEC Rep. LA-3553-MS, Los Alamos Scientific Laboratory (1966).

39. M. J. SAARIVIRTA and P. P. TAUBENBLAT, "Some High-Temperature Properties of Copper-Zirconium and Copper-Chromium High Conductivity Alloys," Thans. Metall. Soc. AIME (Am. Inst. Min. Metall. Pet. Eng.) 218 (Oct. 1960), p 935.

40. W. R. ELLIS and others, USAEC Rep. LA-5656-PR, Los Alamos Scientific Laboratory (1974), Table II-1.

41. J. P. CRAIG, Texas Tech University, Private Communication (1975) .

42. T. E. MCDONALD, Los Alamos Scientific laboratory. Frivate Communication (1975). 
TABLE I

LTPF PARAMETERS WHICH ARE COMMON TO BOTH POINT DESIGNS (A AND B)

Quantity

Beta

Ion temperature

Compression Coil Radius

Shock-Coil Radius

Test-Sample Radius

Discharge Tube Radius

Electric Field

Quality Factor

Power Consumption

End-Loss Coefficient

Maximum Magnetic Field
Symbo1

$\beta$

$T_{i}$ (or $T$ )

$\mathrm{b}_{2}$

$\mathrm{b}_{\mathrm{SH}}$

$\mathrm{b}_{\mathrm{s}}$

$\mathrm{b}_{1}$

$\mathrm{E}_{\theta}$

Q

$\mathbf{P}$

$\alpha$

$B_{\max }$
Value

1

$5.0 \mathrm{keV}$

$7.0 \mathrm{~cm}$

$6.5 \mathrm{~cm}$

$5.5 \mathrm{~cm}$

$5.0 \mathrm{~cm}$

$1.0 \mathrm{kV} / \mathrm{cm}$

15

$300 \mathrm{MW}$

0.5

$300 \mathrm{kG}$ 
LTPF PARAMETERS FOR POINT DESIGN A

(CONT INUOUS SINUSOIDAL WAVEFORM)

\section{THETA-PINCH PARAMETERS}

Quantity

Duty factor

Mirror magnetic field

l'nmi rrored magnetic field

Mirror ratio

Burn time

Cycle time

Rise time

Cycle frequency

$\mathrm{T}_{\mathrm{e}} / \mathrm{T}_{\mathrm{i}}$

Electron temperature

Storaged magnetic energy

Plasma length

Plasma radius

Plasma radius/gyroradius

Ion density

Lawson Parameter
Symbo1



$B_{\text {max }}$

${ }^{B} \theta$

$\mathrm{R}$

$\tau_{b}$

$\tau_{c}$

$\tau \mathbf{r}$

f

$\lambda$

$\mathrm{T}_{\mathrm{e}}$

$E_{M}$

$\mathrm{L}$

a

$a / r_{L}$

$\mathrm{n}$

$\mathrm{nT}_{\mathrm{b}}$

\section{Value}

3

$300 \mathrm{kG}$

$57.7 \mathrm{kG}$

5.2

$10 \mu \mathrm{ss}$

30 us

$10 \mu \mathrm{s}$

$33 \mathrm{kHz}$

0.040

$200 \mathrm{eV}$

$135 \mathrm{~kJ}$

$66.5 \mathrm{~cm}$

$1.32 \mathrm{~cm}$

4.67

$1.57 \times 10^{16} \mathrm{~cm}^{-3}$

$1.57 \times 10^{11} \mathrm{~cm}^{-3}-5$

NEUTRONICS PARAMETERS

\section{Quantity}

Average primary neutron current $\langle J\rangle$

Average primary neutron flux

Average total neutron flux

Instantaneous total neutron flux

Primary neutron fluence/pulse

Primary neutron fluence/day

Primary neutron fiuence/yr.

Primary neutron source strength
Symbo1

$\langle\phi\rangle \sim 2\langle\mathrm{~J}\rangle$

$\langle\phi\rangle_{\mathrm{T}} \sim 10\langle\phi\rangle$

$\phi_{T}=\left(\sim_{c} / \tau_{b}\right)\langle\phi\rangle T$

$F_{p}=\left(\tau_{c}\right)\langle J\rangle$

$\mathrm{F}_{\mathrm{d}}=86,400^{\mathrm{a}}\langle\mathrm{J}\rangle$

$F_{y}=\left(3.154 \times 10^{7}\right)^{b}\langle\mathrm{~J}\rangle$

$S^{y}=\left(2 \pi b_{S} L\right)\langle J\rangle$

\section{Value}

$4.78 \times 10^{13} \mathrm{n} / \mathrm{cm}^{2}-\mathrm{s}$

$9.56 \times 10^{13} \mathrm{ri} / \mathrm{cm}^{2}-5$

$9.56 \times 10^{14} \mathrm{n} / \mathrm{cm}^{2}-\mathrm{s}$

$2.87 \times 10^{15} \mathrm{n} / \mathrm{cm}^{2}-\mathrm{s}$

$1.43 \times 10^{9} \mathrm{n} / \mathrm{cm}^{2} /$ pulse

$4.13 \times 10^{18} \mathrm{n} / \mathrm{cm}^{2} /$ day

$1.51 \times 10^{21} \mathrm{n} / \mathrm{cm}^{2} / \mathrm{yr}$

$1.10 \times 10^{17} \mathrm{n} / \mathrm{s}$

a number of seconds per day

b number of seconds per year 
LTPF PARAMETERS FOR POINT DESIGN B

(INTERMITTENT TRAPEZOIDAL WAVEFORM)

THETA-PINCH PARAMETERS

\section{Quantity}

Duty factor

Minor magnetic field

Unmirrored magnetic field

Mirror ratio

Burn time

Cycle time

Rise time

Cycle frequency

$\mathrm{T}_{\mathrm{e}} / \mathrm{T}_{\mathrm{i}}$

Electron temperature

Stored magnetic energy

Plasina length

Plasma radius

Plasma radius/gyroradius

Ion density

Lawson parameter
Symbol

$\tau_{c} / \tau_{b}$

${ }_{\text {max }}$

$\mathrm{B}_{\mathrm{O}}$

R

$\tau_{b}$

$\tau_{c}$

$\tau^{\tau} r$

f

$\lambda$

$\mathrm{T}_{\mathbf{e}}$

$\mathrm{E}_{\mathrm{M}}$

L

a

$a / r_{L}$

$\mathrm{n}$

$n \tau_{b}$
Value

53

$300 \mathrm{kG}$

$150 \mathrm{kG}$

2

$10 \mu \mathrm{s}$

$530 \mu \mathrm{s}$

$10 \mu \mathrm{s}$

$1.9 \mathrm{kH}_{z}$

0.122

$610 \mathrm{eV}$

$2.39 \mathrm{MJ}$

$173 \mathrm{~cm}$

$0.86 \mathrm{~cm}$

7.9

$9.87 \times 10^{16} \mathrm{~cm}^{-3}$

$9.87 \times 10^{11} \mathrm{~cm}^{-3} \mathrm{~s}$

\section{NEUTRONICS PARAMETERS}

\section{Quantity}

Average primary neutron current

Average primary neutron flux

Average total neutron flux

Instantaneous total neutron flux

Primary neutron fluence/pulse

Primary neutron fluence/day

Primary neutron fluence/yr

Primary neutron source strength

a

b

\footnotetext{
number of seconds per day

number of seconds per year
}

Symbol

$\langle$ J $\rangle$

$\langle\phi\rangle \sim 2\langle\mathrm{~J}\rangle$

$\langle\phi\rangle_{\mathrm{T}} \sim 10\langle\phi\rangle$

$\phi_{T}=\left(\tau_{c} / \tau_{b}\right)\langle\phi\rangle_{T}$

$F_{p}=\left(\tau_{c}\right)\langle J\rangle$

$\mathrm{F}_{\mathrm{d}}=86,400^{\mathrm{a}}\langle\mathrm{J}\rangle$

$F_{y}=\left(3.154 \times 10^{7}\right)^{b}\langle J\rangle$

$S=\left(2 \pi b_{s} L\right)\langle J\rangle$
Value

$4.57 \times 10^{13} \mathrm{n} / \mathrm{cm}^{2}-\mathrm{s}$

$9.14 \times 10^{13} \mathrm{n} / \mathrm{cm}^{2}-\mathrm{s}$

$9.14 \times 10^{14} \mathrm{n} / \mathrm{cm}^{2}-\mathrm{s}$

$4.84 \times 10^{16} \mathrm{n} / \mathrm{cm}^{2}-\mathrm{s}$

$2.42 \times 10^{9} \mathrm{n} / \mathrm{cm}^{2} /$ pulse

$3.95 \times 10^{13} \mathrm{n} / \mathrm{cm}^{2} /$ day

$1.44 \times 10^{21} \mathrm{n} / \mathrm{cm}^{2} / \mathrm{yr}$

$2.73 \times 10^{17} \mathrm{n} / \mathrm{s}$ 


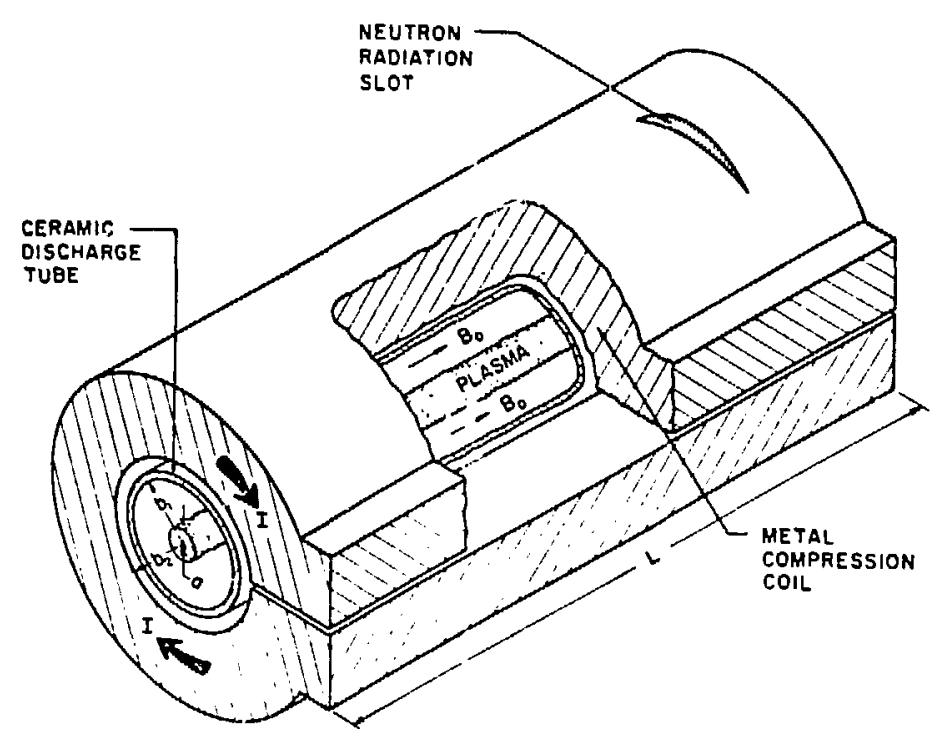

Fig. 1. Linear theta-pinch geometry.

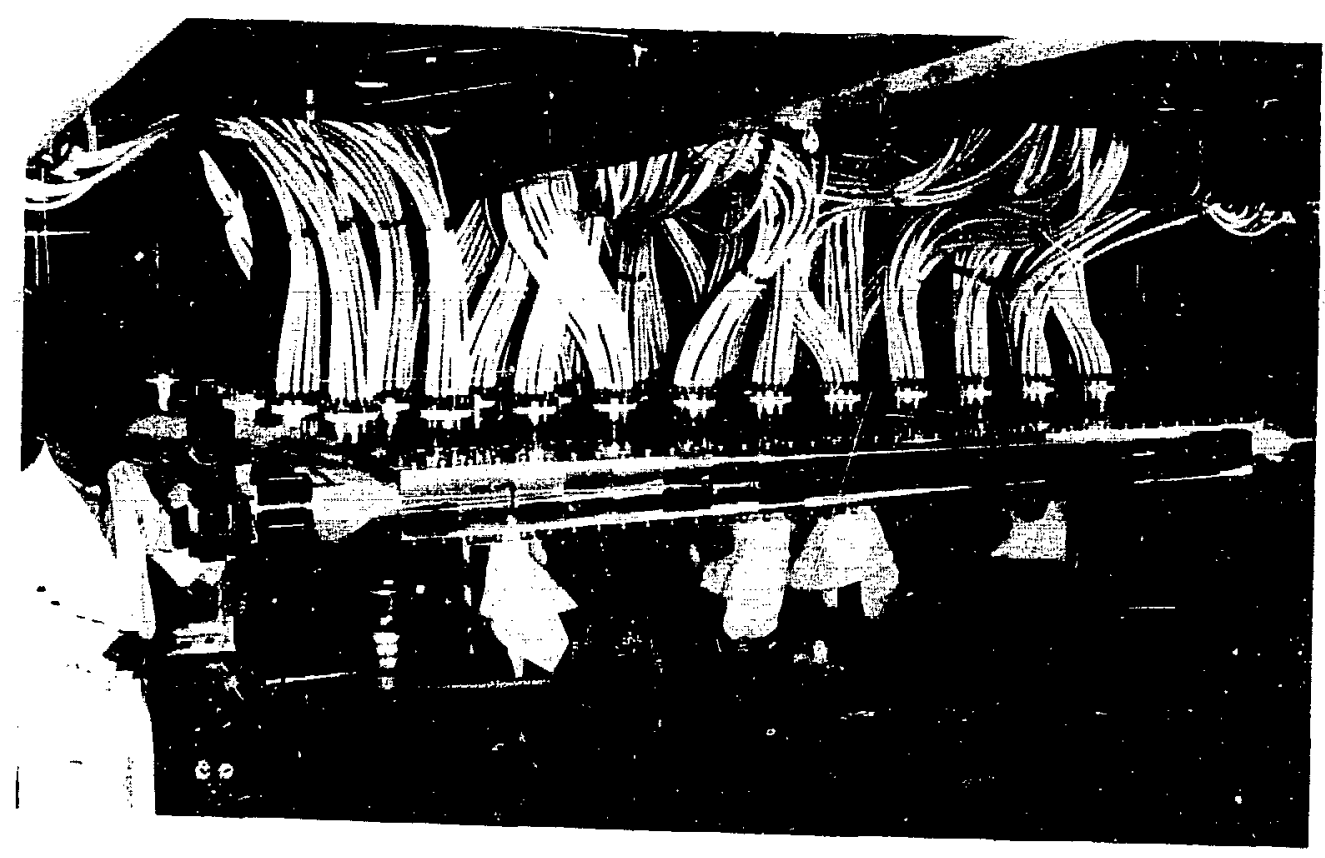

Fig. 2. Photograph of the Scylla IV-3 device, a 3-meter linear theta pinch at LASL. 


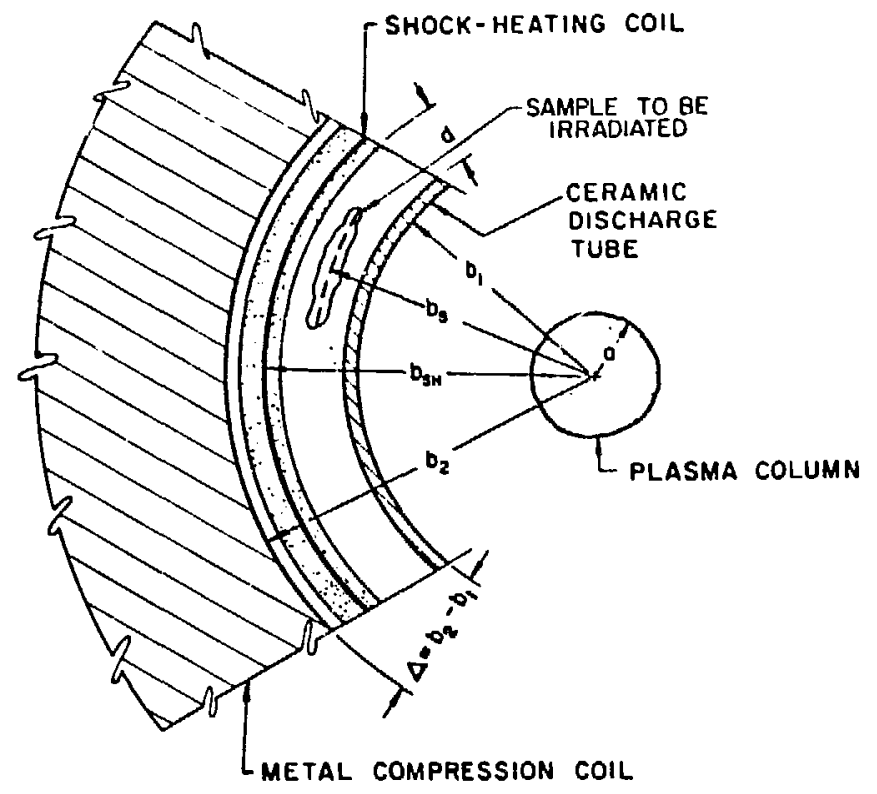

Fig. 3. Cross-sectional view of LTPF, showing test sample location and shock-heating coil.

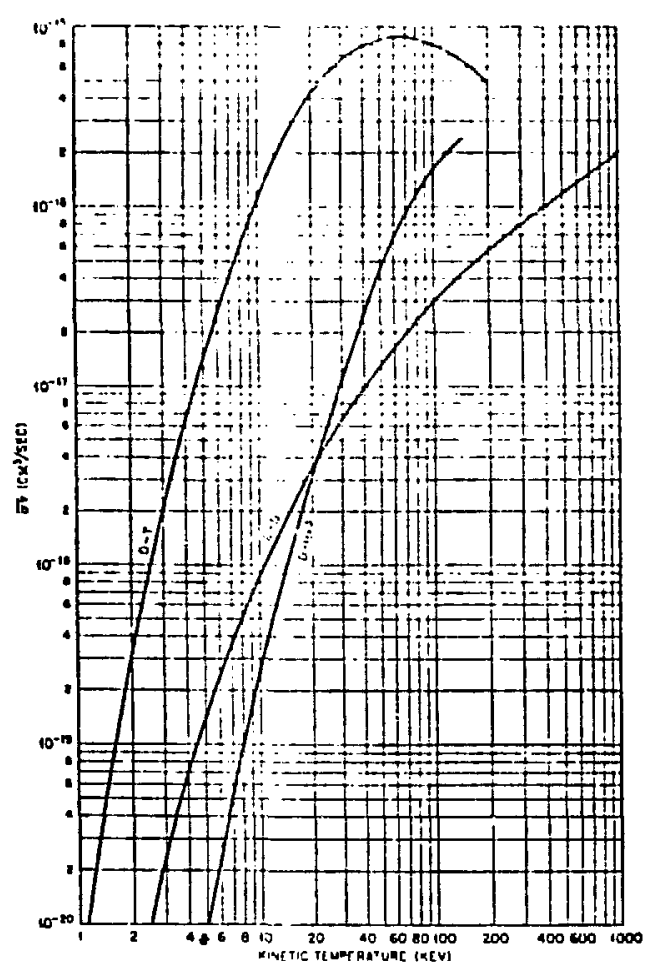

Fig. 4 Curves of $\overline{\sigma V}(T)$ for $D-T, D-D$ (total) and $D-H_{e}^{3}$ fusion reactions [taken from Ref. 10]. 


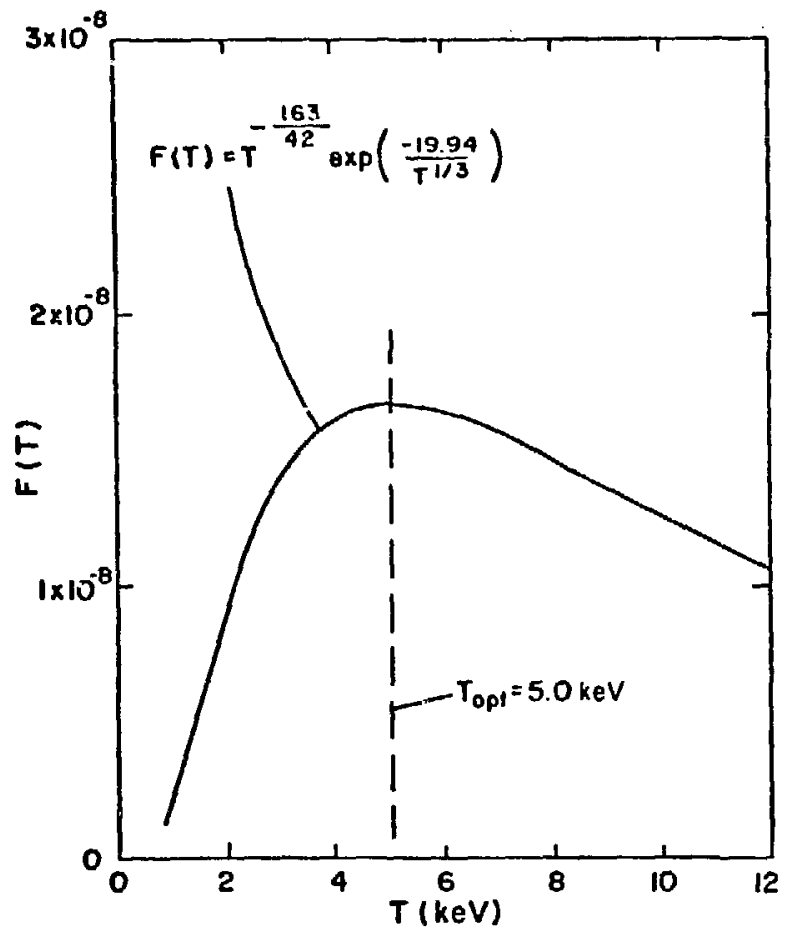

F1g. 5. Temperature dependence, F(T), of the 14-MeV neutron current through a test sample located at radius $b_{s}$.

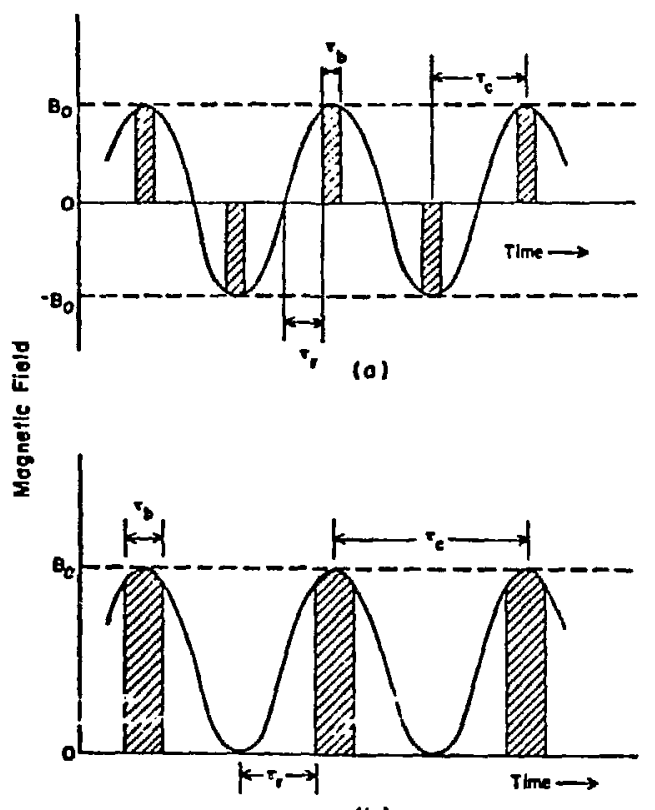

(b)

Fig. 6. Two possible sinusoidal waveforms: (a) $B(t)=B_{0}$ sin $\omega t$;

(b) $B(t)=B_{0}(1+\sin \omega t) / 2$. 


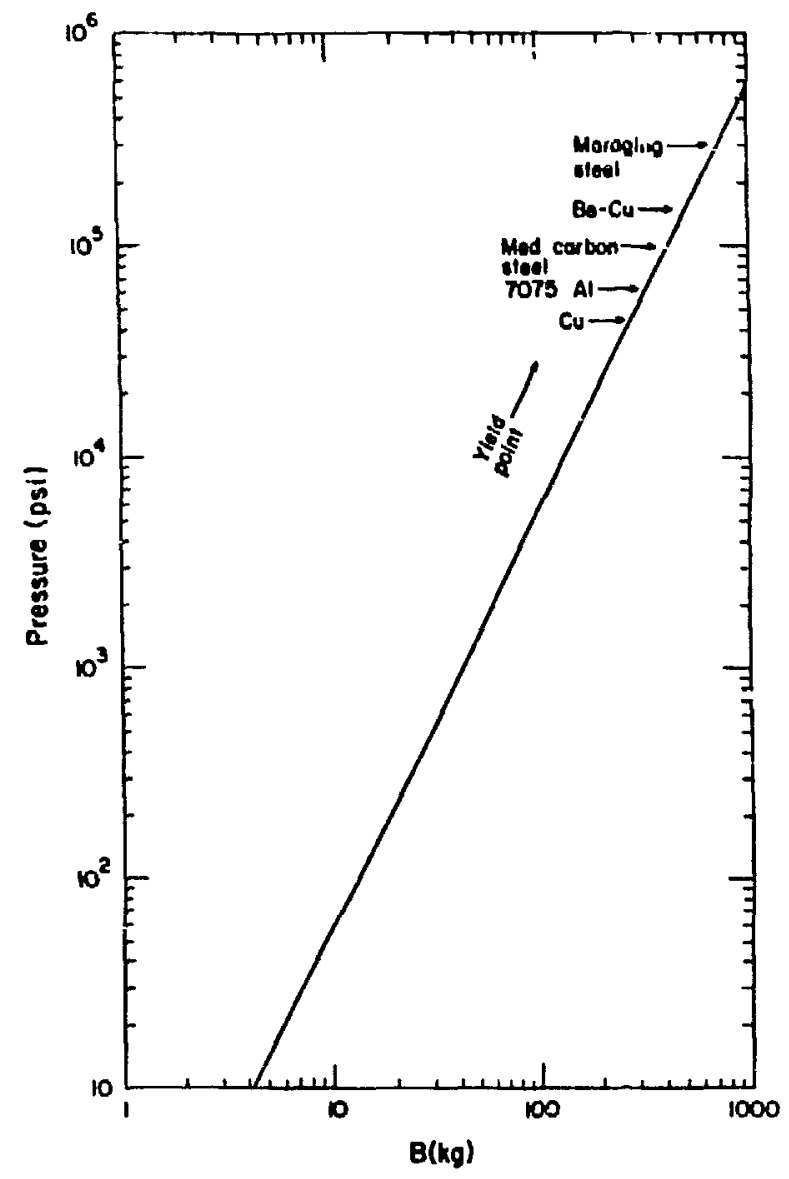

Fig. 7. Yield polnts of some possible coll materials as a function of magnetic fleld strength.

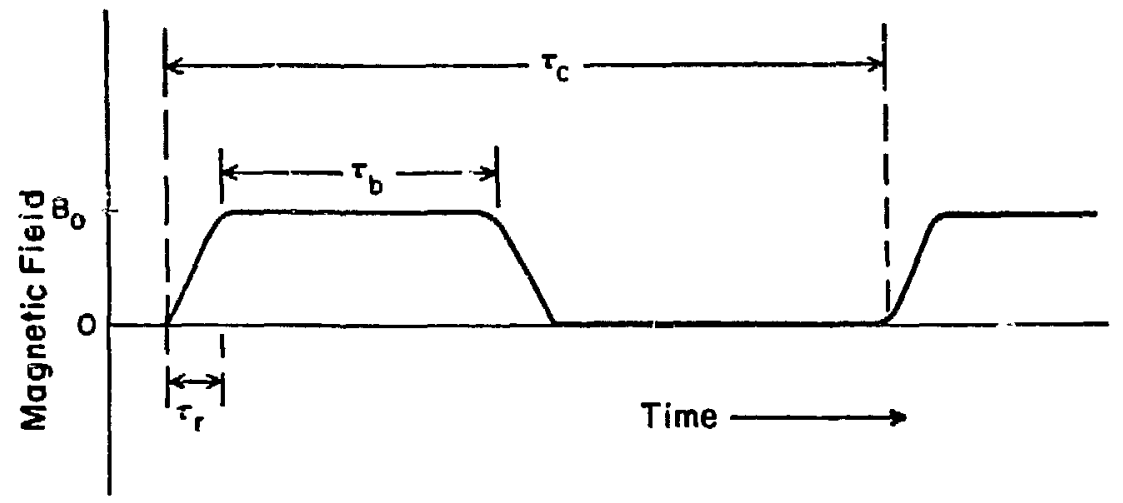

Fig. 8. Illustrating an intermittent trapezoidal magnetic field waveform. 